\title{
Nitric Oxide Pollutant Formation in High Hydrogen Content (HHC)
} Syngas Flames

\author{
K.K. J. Ranga Dinesh ${ }^{1 *}$, J.A. van Oijen ${ }^{2}$, K.H. Luo ${ }^{3}$, X. Jiang ${ }^{4}$ \\ ' Faculty of Engineering and the Environment, University of Southampton, Southampton, \\ SO17 1BJ, UK. \\ ${ }^{2}$ Combustion Technology, Department of Mechanical Engineering, Eindhoven University of \\ Technology, 5600 MB Eindhoven, The Netherlands. \\ ${ }^{3}$ Department of Mechanical Engineering, University College London, Torrington Place, \\ London, WC1E 7JE, UK. \\ ${ }^{4}$ Engineering Department, Lancaster University, Lancaster, Lancashire, LA1 4YR, UK.
} 5

" Corresponding Author: K.K.J. Ranga Dinesh, Energy Technology Research Group, Faculty of Engineering and the Environment, University of Southampton, Southampton, SO17 1BJ, UK.

Email: Dinesh.Kahanda-Koralage@ @oton.ac.uk

Tel: +44 (0) 2380598301

\section{Revised Manuscript Prepared for the International Journal of Hydrogen Energy}

\section{August 2015}


41 Three-dimensional direct numerical simulations (DNS) of high hydrogen content (HHC) syngas nonpremixed jet flames with a Reynolds number of $\mathrm{Re}=6000$ have been carried out to study the nitric oxide (NO) pollutant formation. The detailed chemistry employed is the GRI 3.0 updated with the influence of the NCN radical chemistry using flamelet generated manifolds (FGM). Preferential diffusion effects have been considered via FGM tabulation and the reaction progress variable transport equation.

The DNS based quantitative results indicate a strong correlation between the flame temperature and NO concentration for the pure hydrogen flame, in which NO formation is mainly characterised by the Zeldovich mechanism. The results also indicate a rapid decrease of maximum $\mathrm{NO}$ values in $\mathrm{H}_{2} / \mathrm{CO}$ syngas mixtures due to lower temperatures associated with the CO-dilution into $\mathrm{H}_{2}$. Results on $\mathrm{NO}$ formation routes in $\mathrm{H}_{2} / \mathrm{CO}$ syngas flames show that while the Zeldovich mechanism dominates the NO formation at low strain rates, the high NO formation rate at high strain rates is entirely caused by the NNH mechanism. We also found that the Fenimore mechanism has a least contribution on $\mathrm{NO}$ formation in $\mathrm{H}_{2} / \mathrm{CO}$ syngas flames due to absence of $\mathrm{CH}$ radicals in the oxidation of $\mathrm{CO}$. It is found that, due to preferential diffusion, NO concentration exhibits higher values near the flame base depending on the hydrogen content in $\mathrm{H}_{2} / \mathrm{CO}$ syngas fuel mixture.

Key Words: Syngas, Direct Numerical Simulation, Preferential Diffusion, Zeldovich Mechanism, NNH Mechanism 


\section{Introduction}

In moving towards cleaner combustion technologies, high hydrogen content (HHC) alternative fuel blends are undoubtedly significant, because they are environmentally friendly and can be used as an alternative feedstock for energy resources in clean energy conversion [1-2]. There is a significant current interest in combustion of HHC syngas fuels with a broader reactant class such as hydrogen diluted with carbon monoxide. As with any fuel, the combustion of HHC syngas fuel can produce gaseous pollutant such as nitric oxides $\left(\mathrm{NO}_{\mathrm{x}}\right)$, carbon monoxide $(\mathrm{CO})$, sulphur dioxide $\left(\mathrm{SO}_{2}\right)$, volatile organic compounds (VOCs) etc. which cause a substantial negative impact on the environment. While the HHC syngas fuel burning has abilities to lower $\mathrm{CO}_{2}$ emissions, the $\mathrm{NO}$ formation is critical as a pollutant, which is sensitive to local flame temperature, $\mathrm{O}$ atom concentrations and residence times at the NO forming conditions [3-4]. Progress with respect to further reduction of NO levels in syngas as a major pollutant requires better understanding the burning issues of clean fuels and their correlation with the pertinent chemical kinetics. Currently there is a significant interest in better understanding the NO formation in HHC syngas flames and particularly the different NO mechanisms with respect to HHC syngas fuel variability.

Many theoretical, experimental and computational efforts have been devoted to identifying mechanisms of the NO formation in turbulent jet flames. There is a wealth of experimental investigations available for NO formation in turbulent hydrogen, methane and methane/hydrogen blended nonpremixed jet flames, which includes effects of residence time on NO levels [5], NO formation and its relationship to flame temperature [6], radiation effects on NO concentration [7], and NO formation during the flame vortex interactions [8]. 
effects of hydrogen addition on NO formation in fuel-rich and fuel-lean ethane, propane and $\mathrm{CH}_{4} / \mathrm{O}_{2} / \mathrm{N}_{2}$ flames $[12,13]$ were also reported in the literature.

In the meantime, several computational studies of NO concentration of turbulent jet flames were also carried out. For example, stochastic modelling of NO concentration in premixed methane combustion [14], prediction of NO concentration in hydrogen nonpremixed jet flame [15], tabulation of NO chemistry for large eddy simulation of turbulent nonpremixed combustion [16], prediction of NO concentration with radiation in nonpremixed flames [17] and prediction of NO concentration in lean premixed flames [18] were also reported. In addition, several other research questions relevant to NO formations have been addressed by numerical modelling on turbulent flames, which include recent investigations of influence of airstream dilution and jet velocity on $\mathrm{NO}$ emission characteristics of $\mathrm{CH}_{4}$ bluff-body flames [19], the formation/destruction mechanisms of $\mathrm{NO}$ in $\mathrm{CH}_{4} / \mathrm{H}_{2}$ jet flames in a hot co-flow [20] and the effects of hydrogen addition on NO characteristics in MILD (Moderate or Intense Low-oxygen Dilution) combustion of $\mathrm{CH}_{4} / \mathrm{H}_{2}$ fuel blends [21].

However, only a few investigations focused on NO formations of hydrogen-rich to hydrogenlean $\mathrm{H}_{2} / \mathrm{CO}$ syngas flames for laboratory scale fundamental flames as well as practical engine like conditions. For example, experimental and numerical investigations on nitric oxide formation in laboratory scale $\mathrm{H}_{2} / \mathrm{CO}$ jet flames have been reported in the recent literature. These include experimental investigations such as NO emission characteristics and scaling of $\mathrm{H}_{2} / \mathrm{CO}$ syngas flames [22], assess $\mathrm{NO}$ production from different formation routes from syngas and biogas fuel blends [23] as well as numerical studies such as effects of syngas composition and diluents on emission characteristics of syngas nonpremixed flames [24], effects of the fuel-side nitrogen dilution on the structure and $\mathrm{NO}_{\mathrm{x}}$ formation characteristics of syngas nonpremixed flames [25], and effects of syngas composition, pressure and dilution 
gases on the $\mathrm{NO}_{\mathrm{x}}$ emission of $\mathrm{H}_{2} / \mathrm{CO}$ syngas nonpremixed flames [26]. Limited advances have been also made in understanding the global $\mathrm{NO}$ formation characteristics of $\mathrm{H}_{2} / \mathrm{CO}$ syngas flames in practical engine like conditions, for example in industrial gas turbine combustor [27] and in spark-ignition direct-injection internal combustion engine [28]. However, detailed understanding on NO formation in turbulent flames with variable fuel compositions is still lacking, particularly with respect to hydrogen-rich to hydrogen-lean $\mathrm{H}_{2} / \mathrm{CO}$ syngas fuel blending.

Over the last several years, computationally intensive direct numerical simulation (DNS) technique which provides detailed information on turbulent reacting flows has been successfully applied to simulate a broad range of combustion problems [29-33]. Many review articles also reported advances in DNS of turbulent combustion, for example [34, 35]. However, despite many DNS investigations of turbulent combustion problems have been carried out including hydrogen combustion, no three-dimensional DNS with detailed chemistry is reported for NO formation of HHC syngas fuel burning in turbulent flames. The aim of the present work is to study the $\mathrm{NO}$ formation in pure hydrogen and $\mathrm{HHC} \mathrm{H}_{2} / \mathrm{CO}$ syngas turbulent nonpremixed jet flames using DNS and flamelet generated manifold (FGM) tabulated chemistry [36], and to explore the possibility of better understanding the behaviour of basic mechanisms of NO formations for high hydrogen content nonpremixed syngas burning. This new work on investigation of NO formation in HHC syngas fuel mixture with the influence of preferential diffusion is a continuation of our previous DNS investigations focused on burning characteristics of $\mathrm{H}_{2} / \mathrm{CO}, \mathrm{H}_{2} / \mathrm{CO} / \mathrm{CO}_{2}, \mathrm{H}_{2} / \mathrm{CO} / \mathrm{CO}_{2} / \mathrm{N}_{2}$ syngas combustion [37], effects of preferential diffusion on hydrogen-rich to hydrogen-lean $\mathrm{H}_{2} / \mathrm{CO}$ syngas combustion [38], influence of chemical reactions on major, minor and radical species 136 concentrations of hydrogen-rich to hydrogen-lean $\mathrm{H}_{2} / \mathrm{CO}$ syngas burning [39], analysis of the 
137 Wobbe index, flame index, flame normal, flame surface and a micromixing process of hydrogen-rich to hydrogen-lean $\mathrm{H}_{2} / \mathrm{CO}$ syngas flames [40], and turbulence-chemistry interaction and the local flame extinction of $\mathrm{CO}_{2}$-diluted oxy-syngas combustion [41].

Given the nature of HHC turbulent nonpremixed syngas combustion, it is important to ask two key questions: (i) how does NO form with respect to hydrogen content in the HHC syngas fuel mixture in turbulent nonpremixed flames, (ii) how does preferential diffusion influence NO distribution in the HHC syngas fuel mixture in turbulent nonpremixed flames. To answer these two questions, we performed a new set of unsteady compressible threedimensional DNS calculations including a transport equation for the NO mass fraction. The remainder of the paper is organised as follows: the governing equations, chemistry and numerical details are presented in section 2 followed by results and discussion in section 3 . Finally, conclusions and recommendations for further work are presented in section 4.

\section{DNS Equations, Chemistry and Numerical Implementation}

The set of governing equations solved in present DNS for turbulent nonpremixed jet flames is the time-dependent compressible flow Navier-Stokes equations, the energy equations, transport equations of mixture fraction, reaction progress variable and mass fraction of nitric oxide and the state equation. The governing equations for mass, momentum, energy, mixture fraction, reaction progress variable and the state equations in their non-dimensional form can be found in [38]. It is important to note that we added an additional model term for the diffusion term in the transport equation of reaction progress variable in order to include the non-unity Lewis number effects (preferential diffusion). With an additional model term, the non-dimensional transport equation of reaction progress variable, $\mathrm{Y}$ can be written as: 
$161 \frac{\partial(\rho Y)}{\partial t}+\frac{\partial\left(\rho u_{k} Y\right)}{\partial x_{k}}-\frac{1}{\operatorname{Re} \operatorname{Pr}} \frac{\partial}{\partial x_{k}}\left(\frac{\lambda}{C_{p}} \frac{\partial Y}{\partial x_{k}}\right)-\frac{1}{\operatorname{Re} S c_{Y}} \underbrace{\frac{\partial}{\partial x_{k}}\left(\rho D_{Y \xi} \frac{\partial \xi}{\partial x_{k}}\right)}_{\text {additional model term }}-\omega_{Y}=0$,

162 Here the additional term which accounts for non-unity Lewis number explicitly (preferential

163 diffusion) is given by $\frac{\partial}{\partial x_{k}}\left(\rho D_{Y \xi} \frac{\partial \xi}{\partial x_{k}}\right)[38]$.

164 The non-dimensional transport equation for $\mathrm{NO}$ mass fraction, $\mathrm{Y}_{\mathrm{NO}}$ is given by:

165

$\frac{\partial\left(\rho Y_{N O}\right)}{\partial t}+\frac{\partial\left(\rho u_{k} Y_{N O}\right)}{\partial x_{k}}-\frac{1}{\operatorname{RePr}} \frac{\partial}{\partial x_{k}}\left(\frac{\lambda}{C_{p}} \frac{\partial Y_{N O}}{\partial x_{k}}\right)-\omega_{Y_{N O}}=0$.

166 Where $t$ stands for time, $u_{j}$ is the velocity components in the $x_{j}$ direction, $\lambda$ stands for heat

167 conductivity, $C_{P}$ for specific heat at constant pressure, $\xi$ is the mixture fraction, $\omega_{Y}$ is the

168 source term of the progress variable, $\omega_{Y_{N O}}$ is the source term of the NO transport equation, $\rho$

169 is the density, $\rho D_{Y \xi}$ is the additional diffusion coefficient for non-unity Lewis number

170 calculation respectively. In addition, $\mathrm{Pr}, \mathrm{Re}$ and $\mathrm{Sc}_{\mathrm{Y}}$ represent Prandtl number, Reynolds

171 number and Schmidt number respectively.

172

173 The detailed flame chemistry of HHC syngas flames is represented by databases of the FGM

174 tabulated chemistry [36], accounting for both chemical and transport processes using the

175 laminar flamelet concept [42]. In order to demonstrate the NO formation mechanism with

176 respect to reaction between $\mathrm{N}_{2}$ and $\mathrm{CH}$ radicals, we employed detailed chemistry tabulation

177 with recently identified critical radical species NCN and corresponding chemical reactions in

178 this investigation. The FGM tables were created with updated GRI-Mech 3.0 [43] with the

179 NCN radical chemistry. The mechanism contains 54 species, in which 53 species are from 

and 4 reactions involving the NCN radical reactions. The resolution of the manifolds is 301 points in the mixture fraction direction and 101 points in the progress variable direction. For $\mathrm{H}_{2}$-Air combustion, the mass fraction of $\mathrm{H}_{2} \mathrm{O}$ was selected as the progress variable, while for $\mathrm{H}_{2} / \mathrm{CO}$-Air combustion, sum of the mass fractions of $\mathrm{H}_{2} \mathrm{O}, \mathrm{CO}$ and $\mathrm{CO}_{2}$ was selected as the progress variable.

Turbulent nonpremixed round jet flame is adopted as a model problem. The Cartesian cubic configuration of turbulent nonpremixed jet flame including domain size and boundary conditions is shown in Fig. 1. The configuration consists of 10 jet nozzle diameters (10D) in axial direction and 7 jet nozzle diameters (7D) in radial direction. There are $640 \times 640 \times 640$ computational grid points in the $\mathrm{L}_{\mathrm{X}} \times \mathrm{L}_{\mathrm{Y}} \times \mathrm{L}_{\mathrm{Z}}$ cubic computational domain resulting 262 million grid points. The full compressible governing equations noted above are solved using the parallel DNS flame solver, DSTAR [37-41, 44]. The equations are discretised in space on a three-dimensional Cartesian grid with high-order finite difference numerical schemes. Derivatives are computed using centered explicit schemes of order six except at boundaries where the order is progressively reduced to four [45]. Temporal integration is realized with a Runge-Kutta algorithm of order three [46]. A CourantFriedrichs-Levy (CFL) condition for the convective terms is treated to ensure the stability of the explicit integration and determine a suitable time step. All simulations were performed at 200 a Reynolds number of 6,000. Boundary conditions are treated with the help of non-reflecting inflow/outflow Navier-Stokes characteristics boundary condition (NSBC) [47]. The inflow mean axial velocity is specified using a hyperbolic tangent profile with profile 
204 direction of the round jet, originating from the centre of the inlet 205 domain $\left(0 \leq x \leq L_{x}, 0 \leq y \leq L_{v}\right)$. The initial momentum thickness $\delta$ was chosen to be $10 \%$ of 206 the jet radius. The inflow turbulent fluctuations were artificially generated in a sinusoidal 207 form and added to all three velocity components. The boundary conditions for scalars such as mixture fraction and reaction progress at outlet boundary were specified with zero-gradient. Table 1 summarised the fuel compositions of the three numerically simulated HHC flames $\mathrm{H}$, $\mathrm{HCO} 1$ and $\mathrm{HCO} 2$, their stoichiometric mixture fractions, adiabatic flame temperatures, and physical and numerical parameters for turbulent round jet configuration.

\section{Results and Discussion}

214 In the following, the NO formation mechanisms and results are presented and discussed 215 under three sections with two principal aims. The first section discusses basic mechanisms of 216 NO formation. The second section compares the NO formation of pure hydrogen flame $\mathrm{H}$ 217 between the unity Lewis number case and the non-unity Lewis number case. This section also discusses comparison between the DNS data and the experimental measurements in order to demonstrate the accuracy of DNS based NO prediction with the influence of preferential diffusion. The third and final section discusses the NO distributions of pure hydrogen flame $\mathrm{H}, \mathrm{H}_{2} / \mathrm{CO}$ syngas flames $\mathrm{HCO} 1$ and $\mathrm{HCO} 2$ with the influence of preferential diffusion by highlighting corresponding basic NO mechanisms and dominant chemical reactions. The results are discussed in several forms which include instantaneous contour plots, one-point data analysis and probability density function distributions. Subsequently, important chemical reactions and mechanisms for NO formation are highlighted, where $\mathrm{HHC}$ fuels are unique in terms of pollutant formation during combustion. 


\subsection{Basic mechanisms of NO formation}

229 Generally, there are two well-known routes for NO formation in combustion environments, namely the thermal-NO [48] and prompt-NO [49] mechanisms. Moreover, there exist two

231 additional routes for $\mathrm{NO}$ formations, known as the $\mathrm{N}_{2} \mathrm{O}$ route [50] and the $\mathrm{NNH}$ route [51]. The thermal $\mathrm{NO}$ mechanism involves breaking up $\mathrm{N}_{2}$ triple-bond by $\mathrm{O}$ atoms at high temperature, which includes two principal reactions proposed by Zeldovich [48]:

$$
\mathrm{N}_{2}+\mathrm{O} \leftrightarrow \mathrm{N}+\mathrm{NO}
$$

$\mathrm{N}+\mathrm{O}_{2} \leftrightarrow \mathrm{O}+\mathrm{NO}$

and the reaction of $\mathrm{N}$ atom with $\mathrm{OH}$ radical:

$\mathrm{N}+\mathrm{OH} \leftrightarrow \mathrm{NO}+\mathrm{H}$

The Eqs. (3), (4) and (5) involve radical species $\mathrm{O}, \mathrm{N}, \mathrm{H}$ and $\mathrm{OH}$ that are initially formed through decomposition or abstraction reactions. Due to the inherent stability of the $\mathrm{N}_{2}$ molecule, considerable energy is required to oxidise $\mathrm{N}_{2}$, and thus thermal $\mathrm{NO}$ is only formed in appreciable quantities at temperatures approximately above $1700 \mathrm{~K}$.

The Fenimore's prompt-NO mechanism [49] involves reaction between $\mathrm{N}_{2}$ and $\mathrm{CH}$ radicals which was originally described through $\mathrm{HCN}$ such that:

$$
\mathrm{CH}+\mathrm{N}_{2} \leftrightarrow \mathrm{HCN}+\mathrm{N}
$$

However, recent studies have shown that the NCN radical is the major pathway to prompt $\mathrm{NO}$ for the reaction $\mathrm{CH}+\mathrm{N}_{2}$ [52]. In the present work, we consider the NCN radical pathway to study prompt-NO, which includes two major reactions [53]:

$\mathrm{CH}+\mathrm{N}_{2} \leftrightarrow \mathrm{NCN}+\mathrm{H}$

$\mathrm{C}_{2} \mathrm{O}+\mathrm{N}_{2} \leftrightarrow \mathrm{NCN}+\mathrm{CO}$

The $\mathrm{N}_{2} \mathrm{O}$ route [50] is originated by the $\mathrm{N}_{2} \mathrm{O}$ interaction with radicals $\mathrm{H}$ or $\mathrm{O}$ and yield $\mathrm{NO}$ and can be described by the following elementary reactions: 
$\mathrm{N}_{2} \mathrm{O}+\mathrm{O} \leftrightarrow \mathrm{N}_{2}+\mathrm{O}_{2}$

The NNH route [51] takes place due to the reaction of $\mathrm{H}$ radicals with $\mathrm{N}_{2}$ and it is likely that the $\mathrm{NNH}$ route can have an important role in the hydrogen combustion primarily at short residence times [54] and includes reactions:

and the reaction of $\mathrm{NNH}$ and $\mathrm{O}$ has the following channels: $\mathrm{NH}+\mathrm{NO}, \mathrm{N}_{2} \mathrm{O}+\mathrm{H}$ and $\mathrm{N}_{2}+\mathrm{OH}$ [51].

\subsection{Preferential diffusion effects on NO formation in hydrogen flame H}

In order to identify the influence of preferential diffusion on NO formation and distribution, we compare instantaneous three-dimensional NO structures, and scattered data of NO mass fraction in the mixture fraction space between the unity Lewis number and the non-unity Lewis number cases as shown in Fig.2. Three-dimensional structure of mass fraction of NO displays local increase of NO values with strong vortical structures in shear layer region and outer region layer in the non-unity Lewis number case compared to the unity Lewis number case. It is seen from the unity-Lewis number three-dimensional structure that the high NO zone is insensitive to steady straining in the absence of non-unity Lewis number. This confirms that the strain rate effects remain closely tied to non-unity Lewis number and preferential diffusion effects and therefore NO formation for hydrogen flame H. Fig. 2 (bottom) shows scattered NO values of the full domain and the near nozzle region between the unity Lewis number and the non-unity Lewis number. The scattered data of the non-unity 
Lewis number case show much higher NO values compared to the unity Lewis number case for each mixture fraction range of $\mathrm{NO}$ values around the stoichiometric mixture fraction region, and on the fuel-lean side.

In order to evaluate the success of DNS predictions of quantitative NO values, we now discuss the comparison of mass fraction of NO values with the closest possible experimental data of turbulent nonpremixed hydrogen jet flame carried out by Barlow and Carter [6]. Fig. 3 shows comparisons for scattered data of NO values between DNS values (a1, b1, c1) and the experimental data $(\mathrm{a} 2, \mathrm{~b} 2, \mathrm{c} 2)$ at three different downstream axial locations $\mathrm{z}=4,8$ and 10 . It is important to note that DNS of nonpremixed hydrogen jet flame was performed at a Reynolds number of 6000 , while experimental investigation was carried out at a much higher Reynolds number of 10000. With two different Reynolds numbers, one can expect differences in the jet shear layer on the developing flames. For example, the shear layer dynamics affect the internal chemical structure including NO formation. Despite the difference of Reynolds number and its influence on flow field and flame structure, the comparison between DNS data and the experimental measurements show reasonably good agreement at all three axial locations. Particularly, we observe the occurrence of peak NO values on fuel lean side close to stoichiometric mixture fraction of 0.028 for DNS data (Fig. 3 (a1, b1, c1)). This has been also observed by the experimental measurements (Fig. 3 (a2, b2, c2)). In summary, the comparison between DNS results and the experimental measurements indicates that our DNS results with the inclusion of preferential diffusion reasonably predict the NO formation and its distribution in turbulent nonpremixed hydrogen flame. 

with the influence of preferential diffusion

Instantaneous cross-sectional mid-plane contour plots of flame temperature and mass fraction of $\mathrm{NO}$ at non-dimensional time instant $\mathrm{t}=30$ are shown in Fig.4. To obtain an idea of the temperature distribution and NO formation more locally, and to facilitate the subsequent onepoint data analysis, the flames are divided into three different zones, defined as the upstream zone A $(0<z<2)$, intermediate zone B $(2<z<8)$ and downstream zone $C(8<z<10)$. The flame structures between the three cases show large differences with respect to CO-dilution, which is a regulated pollutant and a component of unburned syngas, resulting from inefficient mixing that yields equivalence ratio outside the ignition range and an incomplete combustion of hydrocarbon species in the syngas. The flame temperatures of the three flames show a decreasing maximum value but an increasing vortical level from flames $\mathrm{H}$ to $\mathrm{HCO} 1$ and $\mathrm{HCO} 2$, because of the decreasing hydrogen content and the increasing $\mathrm{CO}$ content in $\mathrm{H}_{2} / \mathrm{CO}$ syngas fuel mixture. Moreover, temperature distributions in Fig.4 show intense burning and strong flame width for the pure hydrogen flame $\mathrm{H}$, but moderate burning and relatively weak flame width for the $\mathrm{CO}$-diluted $\mathrm{HCO} 1$ and $\mathrm{HCO} 2$ syngas flames depending on the $\mathrm{CO}$ content in syngas fuel mixture. It is important to note that the similar flame appearances were recently observed by Hwang et al. [22] in their experimental investigation for turbulent nonpremixed pure $\mathrm{H}_{2}, \mathrm{H}_{2}$-rich $\mathrm{H}_{2} / \mathrm{CO}$ syngas, and $\mathrm{H}_{2}$ and $\mathrm{CO}$ equally blended $\mathrm{H}_{2} / \mathrm{CO}$ syngas jet flames at Reynolds number of 9000.

Furthermore, as seen in Fig. 4 the distribution of NO mass fraction exhibits some formation near the flame base in zone A for the pure hydrogen flame $\mathrm{H}$. The contour plots indicate a strong correlation between the flame temperature and the mass fractions of NO, particularly for the pure hydrogen flame H. Moreover, as we move downstream in Fig. 4, pockets of high 
NO values are apparent for $\mathrm{H}_{2} / \mathrm{CO}$ syngas flames $\mathrm{HCO} 1$ and $\mathrm{HCO} 2$ at intermediate zone $\mathrm{B}$ and downstream zone $\mathrm{C}$. The rise of $\mathrm{NO}$ concentration of $\mathrm{H}_{2} / \mathrm{CO}$ syngas flames at these pockets may also correspond to regions with high scalar dissipation rate. In addition, large fluid parcels can be observed in the vortical regions of the upstream jet of all cases, as indicated by the distributions of temperature and NO mass fractions, indicating the existence of non-reacting zones associated with the flow structures in the reacting flow field.

For the pure hydrogen flame, NO is mainly formed through the Zeldovich mechanism (Eqs. (3), (4) and 5)) as the Fenimore mechanism cannot occur at all due to the absence of $\mathrm{CH}$ radicals. Furthermore, the formation of NO appears to be rapid for the pure hydrogen flame $\mathrm{H}$, thus indicating possible reaction between $\mathrm{H}$ radicals and $\mathrm{N}_{2}$ via the $\mathrm{NNH}$ mechanism (Eqs. (13) and (14)).

However, $\mathrm{NO}$ formation mechanism in $\mathrm{H}_{2} / \mathrm{CO}$ blended syngas flames is questionable and needs further analysis. To investigate the $\mathrm{NO}$ formation mechanisms in hydrogen-rich $\mathrm{H}_{2} / \mathrm{CO}$ syngas flame HCO1, laminar counterflow flames are computed by using an updated GRI 3.0 mechanism with 54 species and 329 reactions [43]. In the following, the results of two calculations having different strain rates are compared. The strain rates are selected such that one flame is close to chemical equilibrium $\left(a=1 s^{-1}\right)$ and the other is close to extinction $\left(a=1 \times 10^{4} s^{-1}\right)$. Fig.5 (a) and (b) shows the temperature and net NO formation rate as functions of mixture fraction. A high strain induces high gradients and therefore high conductive heat losses, which lead to a relatively low flame temperature. It is observed that the higher temperature of the low strained flame does not lead to a higher NO formation rate. While the Zeldovich mechanism is expected to produce more NO for the low-strained flame, the net formation rate is actually higher for the high-strained flame with the lower temperature. To further investigate this behaviour in hydrogen-rich $\mathrm{H}_{2} / \mathrm{CO}$ syngas flame, the 
contributions of various NO formation mechanisms are analysed. In Fig.6 (a) and (b) the reaction rates of different $\mathrm{NO}$ formation routes are plotted for the two cases. It is found that low strained $\mathrm{H}_{2} / \mathrm{CO}$ syngas flame with the highest flame temperature, the Zeldovich mechanism accounts for almost the total NO production. Other NO formation mechanisms have a negligible contribution. However, in the high strained syngas flame, the Zeldovich formation rate is virtually zero, because of the low temperature. Fig. 6(a) and (b) also show that the Fenimore mechanism is negligible in low and high strain rates cases, because $\mathrm{CH}$ radicals are not formed in the oxidation of CO. Interestingly, we found that the high NO formation rate in the high strained syngas flame is almost exclusively caused by the $\mathrm{NNH}$ route. The high concentration of $\mathrm{H}$ radicals results in a high formation rate of $\mathrm{NNH}$ (Eq. 13). The $\mathrm{NNH}$ radicals then can react with $\mathrm{O}$ radicals to form $\mathrm{NO}$ and $\mathrm{NH}$ (Eq. 14). The $\mathrm{NH}$ radicals subsequently react with various partners to form NO directly or via $\mathrm{N}$ and HNO.

In summary, for hydrogen-rich $\mathrm{H}_{2} / \mathrm{CO}$ syngas flames the $\mathrm{NO}$ formation rate is highest at low flame temperatures, i.e. at high strain (or scalar dissipation) rates. At high temperatures (i.e. at low strain), the Zeldovich mechanism is the main NO formation route, but at low temperatures the NNH route dominates. The Fenimore mechanism has a negligible contribution in low and high strained rates, because the concentration of $\mathrm{CH}$ radicals is practically zero. Moreover, the present findings of NO distribution in hydrogen-rich and hydrogen-lean $\mathrm{H}_{2} / \mathrm{CO}$ syngas flames are also consistent with recent NO study carried out by Shih and Hsu [26] for their one-dimensional laminar opposed-jet syngas nonpremixed flames, in which they found that hydrogen-rich $\mathrm{H}_{2} / \mathrm{CO}$ syngas flames produce $\mathrm{NO}$ emission from Zeldovich and NNH routes.

Figs. 7-9 show the instantaneous scatter plots of flame temperature, mass fraction of NO and source term of the transport equation of $\mathrm{NO}$ versus mixture fraction in zones $\mathrm{A}, \mathrm{B}$ and $\mathrm{C}$. The 
scattered data of pure $\mathrm{H}_{2}$ flame $\mathrm{H}$ does not exhibit local flame extinction for all three zones. It is observed that the range of mixture fraction for pure $\mathrm{H}_{2}$ flame $\mathrm{H}$ is much narrower than $\mathrm{CO}$ diluted flames $\mathrm{HCO} 1$ and $\mathrm{HCO} 2$. As a result of the preferential diffusion effects, the peak temperature occurs on the lean side of the stoichiometric mixture fraction, which are the strongest for the flame $\mathrm{H}$. The wide range of mixture fraction distribution at a fixed temperature can be attributed to the preferential diffusion which enhances the chemical reactions at the molecular level and leads to chemical reactions at leaner conditions with high flame temperatures. However, this behaviour is starting to deviate more towards local extinction with $\mathrm{CO}$ addition to $\mathrm{H}_{2}$. The scattered data of flame temperature of both the flames $\mathrm{HCO} 1$ and $\mathrm{HCO} 2$ show that a wide range of temperature is found in a range of relatively high mixture fraction compared to the pure $\mathrm{H}_{2}$ flame $\mathrm{H}$.

The scatter data of mass fraction of NO between the three flames show noticeable differences in zones $\mathrm{A}, \mathrm{B}$ and $\mathrm{C}$. The pure hydrogen flame $\mathrm{H}$ shows considerably higher flame temperatures for all three zones therefore highest $\mathrm{NO}$ values compared to the CO-diluted $\mathrm{H}_{2} / \mathrm{CO}$ flames. For example, the scatter data of temperature in Figs. 7-9 show the peak values of $2637 \mathrm{~K}$ for pure hydrogen flame $\mathrm{H}, 2480 \mathrm{~K}$ for $\mathrm{H}_{2}$-rich $\mathrm{H}_{2} / \mathrm{CO}$ syngas flame $\mathrm{HCO} 1$ and 2434K for equally blended $\mathrm{H}_{2} / \mathrm{CO}$ syngas flame $\mathrm{HCO} 2$. The NO concentration of flame $\mathrm{H}$ shows the peak values of $150(\mathrm{ppm})$ in zone A, $130(\mathrm{ppm})$ in zone B and over $150(\mathrm{ppm})$ in zone $\mathrm{C}$. This confirms the formation of high NO concentration near the flame base for the hydrogen flame due to high diffusivity, mainly via the Zeldovich mechanism with possible influence from the NNH mechanism. The scatter plots also reveal decrease of the maximum NO value due to lower temperature of the post-flame gas with respect to CO-dilution, thereby reducing the contribution of the Zeldovich mechanism. The NNH mechanism takes place in a thin area of the flame with large concentration of $\mathrm{H}$ radical and therefore can be the dominant 
route of $\mathrm{NO}$ formation in $\mathrm{H}_{2} / \mathrm{CO}$ syngas combustion. For example, the $\mathrm{NO}$ concentration of syngas flame HCO1 shows peak values of 90 (ppm) in zone A, 120 (ppm) in zone B and 110 (ppm) in zone C. A similar trend is also observed for the syngas flame HCO2. Furthermore, more populated $\mathrm{NO}$ concentration forms for the entire mixture fraction range at the upstream zone A for all three flames irrespective of the fuel mixture. However, this behaviour disappears in zone $\mathrm{B}$, where NO concentrations start to compress towards fuel lean side. Similar trends with further compact NO concentrations are observed in zone C.

In addition to the differences found for the NO concentration, differences are also exhibited for the source term of the NO transport equation for all three flames. To identify the distribution between the NO concentration and the source term of the NO transport equation, scatter plots of the source term of the NO transport equation are also plotted in zones $\mathrm{A}, \mathrm{B}$ and $\mathrm{C}$ respectively. For pure hydrogen flame $\mathrm{H}$, densely populated $\mathrm{NO}$ source term particles are found in the fuel lean region with a Gaussian shape distribution. However, as seen in syngas flames $\mathrm{HCO} 1$ and $\mathrm{HCO} 2$, the Gaussian shape is slightly deviated with CO-dilution. It is also noticed that the negative values of NO source term occur for CO-diluted flames $\mathrm{HCO} 1, \mathrm{HCO} 2$, while it shows zero as a minimum value for the undiluted flame $\mathrm{H}$. There is also a considerable difference in the maximum values of the NO source term between the three cases depending on the amount of CO-dilution in the fuel.

To explicitly identify the behaviour of NO formation and its relation with temperature, conditional mean value of mass fraction of $\mathrm{NO}$ as a function of temperature and probability 416 density functions (pdf) of temperature and NO mass fraction are plotted. Fig. 10 shows the 417 conditional mean values of mass fraction of $\mathrm{NO}$ as a function of temperature for pure hydrogen flame $\mathrm{H}$ and $\mathrm{H}_{2} / \mathrm{CO}$ syngas flames $\mathrm{HCO} 1$ and $\mathrm{HCO} 2$. The conditional mean values of NO show considerably high peak for hydrogen flame H compared to syngas flames HCO1 
and $\mathrm{HCO} 2$ at high temperature regions with main contribution from the Zeldovich route. It is also observed in Fig. 8 that $\mathrm{CO}$ addition ( $\mathrm{HCO} 1$ and $\mathrm{HCO} 2)$ tends to reduce the strength of high NO peak value considerably. This effect is presumably due to considerable energy required to oxidise highly stable $\mathrm{N}_{2}$ molecule as the $\mathrm{CO}$-dilution lower the flame temperature and therefore energy level.

Figs. 11 and 12 show pdf of temperature and NO mass fraction for flames H, HCO1 and HCO2. The pdf distribution of pure hydrogen flame $\mathrm{H}$ remains fully Gaussian with significantly high $\mathrm{NO}$ values at high temperature. However, pdfs of $\mathrm{H}_{2} / \mathrm{CO}$ syngas flames HCO1 and HCO2 display a relatively less-Gaussian behaviour compared to pure hydrogen flame H. From Figs. 11 and 12 one can conclude that pdf of NO mass fraction has a large variance for pure hydrogen flame $\mathrm{H}$ in which data points are spread out around the mean and from each other, but relatively a small variance for CO-diluted flames $\mathrm{HCO} 1$ and $\mathrm{HCO} 2$ in which data points tend to be close to the mean values and hence to each other.

It is known that the NO chemistry is sensitive to reactions governing the fuel oxidation and the present results indicate possible avenues for future studies of important interactions between emissions. In particular, further investigation on $\mathrm{NO}-\mathrm{CO}$ interactions and their correlation with main $\mathrm{CO}$ oxidation reaction $\mathrm{OH}+\mathrm{CO} \leftrightarrow \mathrm{H}+\mathrm{CO}_{2}$ flame temperature and effective flame zone residence time of syngas combustion would be of great interest. In the future, NO-CO interactions via the NCN radicals will be investigated in detail, which will help us to further understand how critical pollutants interact with each other in hydrogen-rich and hydrogen-lean syngas combustion. 


\section{Conclusions}

444 Nitric oxide formation in hydrogen and hydrogen-rich $\mathrm{H}_{2} / \mathrm{CO}$ syngas turbulent nonpremixed jet flames have been investigated using direct numerical simulation and tabulated FGM chemistry. Simulations were performed at a Reynolds number of 6000 . The influence of

447 preferential diffusion on nitric oxide formation is checked by comparing DNS results between the unity Lewis number and the non-unity Lewis number cases. Statistics of instantaneous flame temperature, mass fraction of NO, source term of transport equation of $\mathrm{NO}$, conditional mass fraction of $\mathrm{NO}$, and probability density functions of NO from direct numerical simulations were compared for pure hydrogen flame $\mathrm{H}$ and two hydrogen-rich $\mathrm{H}_{2} / \mathrm{CO}$ syngas flames.

The main conclusions are as follows:

a. In pure hydrogen flame and hydrogen-rich syngas flames studied here, the peak temperature occurs on the lean side of the stoichiometric mixture fraction as a result of the preferential diffusion effects associated with the hydrogen content in the fuel mixture, which are the strongest for pure hydrogen flame.

b. Comparing statistics of NO distribution between the unity Lewis number and the nonunity Lewis number showed that preferential diffusion plays a significant role in capturing accurate and higher NO levels depending on the hydrogen content in the fuel mixture.

c. The analysis indicates a strong correlation between the flame temperature and the mass fractions of NO, particularly for the flame $\mathrm{H}$, in which $\mathrm{NO}$ is mainly formed through the Zeldovich mechanism and partially via the NNH mechanism.

d. The results also indicate a decrease of NO concentration values due to the lower temperature of the post-flame gas with respect to $\mathrm{CO}$-dilution in the $\mathrm{H}_{2} / \mathrm{CO}$ syngas 
474

475

476

477

478

479

480

481

482

483

484

485

486

487

mixture, thereby reducing the contribution of the Zeldovich mechanism. To fill the gap, the NNH mechanism takes place in a thin area of the flame with the presence of high concentration of $\mathrm{H}$ radical results in a high formation rate of $\mathrm{NNH}$. The Fenimore mechanism is not found due to absence of $\mathrm{CH}$ radical in the $\mathrm{H}_{2} / \mathrm{CO}$ syngas mixture.

\section{Acknowledgement}

This work was sponsored by the Engineering and Physical Sciences Research Council (EPSRC), under the grant EP/L025051/1. Computing resources on UK National Supercomputer ARCHER funded by the EPSRC grant No. EP/J016381/2 are gratefully acknowledged.

80

\section{1}

82


490

491

492

493

494

495

496

497

498

499

500

501

502

503

504

505

506

507

508

509

510

511

512

1. Winter CJ. Hydrogen energy - Abundant, efficient, clean: A debate over the energysystem-of-change. Int J Hydrogen Energy 2009; 34: S1-S52.

2. Ma F, Li S, Zhao J, Qi Z, Deng J, Naeve N, He Y, Zhao S. A fractal-based quasidimensional combustion model for SI engines fuelled by hydrogen enriched compressed natural gas. Int J Hydrogen Energy 2012; 37: 9892-9901.

3. Christodoulou F, Megaritis A. Experimental investigation of the effects of separate hydrogen and nitrogen addition on the emissions and combustion of a diesel engine. Int $\mathbf{J}$ Hydrogen Energy 2013; 38: 10126-10140.

4. Christodoulou F, Megaritis A. Experimental investigation of the effects of simultaneous hydrogen and nitrogen addition on the emissions and combustion of a diesel engine. Int $\mathbf{J}$ Hydrogen Energy 2014; 39: 2692-2702.

5 Driscoll JF, Chen R, Yoon Y. Nitric oxide levels of turbulent jet diffusion flames: Effects of residence time and damkohler number. Combust Flame 1992; 88: 37-49.

6. Barlow RS, Carter CD. Relationships among nitric oxide, temperature, and mixture fraction in hydrogen jet flames. Combust Flame 1996; 104: 288-299.

7. Frank JH, Barlow RS, Lundquist C. Radiation and nitric oxide formation in turbulent nonpremixed jet flames. Proc Combust Inst 2000; 28: 447-454.

8. Santoro VS, Kyritsis DC, Smooke MD, Gomez A. Nitric oxide formation during flame/vortex interaction. Proc Combust Inst 2002; 29: 2227-2233.

9. Williams BA, Pasternack L. The effects of nitric oxide on premixed flames of $\mathrm{CH}_{4}, \mathrm{C}_{2} \mathrm{H}_{6}$, $\mathrm{C}_{2} \mathrm{H}_{4}$ and $\mathrm{C}_{2} \mathrm{H}_{2}$. Combust Flame 1997; 111: 87-110.

10. Konnov AA, Dyakov IV, De Ruyck J. Nitric oxide formation in premixed flames of $\mathrm{H}_{2}+\mathrm{CO}+\mathrm{CO}_{2}$ and air. Proc Combust Inst 2002; 29: 2171-2177. 
513 11. Herrmann K, Boulouchos K. Nitric oxide detection in turbulent premixed methane/air 514 flames. Proc Combust Inst 2005; 30: 1517-1525.

515 12. Sepman AV, van Essen VM, Mokhov AV, Levinsky HB. The effects of hydrogen 516 addition on Fenimore NO formation in low-pressure, fuel-rich-premixed, burner-stabilized $517 \quad \mathrm{CH}_{4} / \mathrm{O}_{2} / \mathrm{N}_{2}$ flames. Int J Hydrogen Energy 2008; 33:5850-5857.

518 13. Sepman AV, Mokhov AV, Levinsky HB. The effects of hydrogen addition on NO 519 formation in atmospheric-pressure, fuel-rich-premixed, burner-stabilised methane, ethane and 520 propane flames, Int J Hydrogen Energy 2011; 36: 4474-4481.

521 14. Cannon SM, Brewster BS, Smoot LD. Stochastic Modelling of CO and NO in Premixed 522 Methane Combustion. Combust Flame 1998; 113: 135-146.

523 15. Barlow RS, Smith NSA, Chen JY, Bilger RW. Nitric oxide formation in dilute hydrogen 524 jet flames: isolation of the effects of radiation and turbulence-chemistry submodels. Combust 525 Flame 1999; 117: 4-31.

526 16. Skottene M, Rian KE. A study of NOx formation in hydrogen flames. Int J Hydrogen $527 \quad$ Energy 2007; 32: 3572-3585.

528 17. Godel G, Domingo P, Vervisch L. Tabulation of NOx chemistry for Large-Eddy 529 Simulation of non-premixed turbulent flames. Proc Combust Inst 2009; 32: 1555-1561.

530 18. Zoller BT, Allegrini JM, Mass U, Jenny P. PDF model for NO calculations with radiation 531 and consistent $\mathrm{NO}-\mathrm{NO}_{2}$ chemistry in non-premixed turbulent flames. Combust Flame 2011; 532 158: 1591-1601.

533 19. Roy RN, Sreedhara S. A numerical study on the influence of airstream dilution and jet 534 velocity on $\mathrm{NO}$ emission characteristics of $\mathrm{CH}_{4}$ and DME bluff-body flames. Fuel 2015; 142 : $535 \quad 73-80$. 
20. Wang F, Li P, Zhang J, Mei Z, Mi J, Wang J. Routes of formation and destruction of nitrogen oxides in $\mathrm{CH}_{4} / \mathrm{H}_{2}$ jet flames in a hot co-flow. Int J Hydrogen Energy 2015; 40: 62286242.

21. Li P, Wang F, Mi J, Dally BB, Mei Z, Zhang J, Parente A. Mechanisms of NO formation in MILD combustion of $\mathrm{CH}_{4} / \mathrm{H}_{2}$ fuel blends. Int J Hydrogen Energy 2014; 39: 19187-19203. 22. Hwang J, Sohn K, Bouvet $\mathrm{N}$, Yoon $\mathrm{Y}$. $\mathrm{NO}_{\mathrm{x}}$ scaling of syngas $\mathrm{H}_{2} / \mathrm{CO}$ turbulent nonpremixed jet flames. Combust Sci Tech 2013; 185: 1715-1734.

23. Watson GMG, Munzar JD, Bergthorson JM. NO formation in model syngas and biogas blends, Fuel 2014; 124: 113-124.

24. Giles DE, Som S, Aggarwal SK. $\mathrm{NO}_{\mathrm{x}}$ emission characteristics of counterflow syngas diffusion flames with airstream dilution. Fuel 2006; 85: 1729-1742.

25. Lee J, Park S, Kim Y. Effects of fuel-side nitrogen dilution on structure and $\mathrm{NO}_{\mathrm{x}}$ formation of turbulent syngas non-premixed jet flames. Energy Fuels 2012; 26: 3304-3315.

26. Shih HY, Hsu JR. Computed NOx emission characteristics of opposed-jet syngas diffusion flames. Combust Flame 2012; 159: 1851-1863.

27. Lee MC, Seo SB, Yoon J, Kim M, Yoon Y. Experimental study on the effect of $\mathrm{N}_{2}, \mathrm{CO}_{2}$, and steam dilution on the combustion performance of $\mathrm{H}_{2}$ and $\mathrm{CO}$ synthetic gas in an industrial gas turbine. Fuel 2012; 102:431-438.

28. Hagos, F. Y, Aziz, A.R. A, Sulaiman S.A. Syngas $\left(\mathrm{H}_{2} / \mathrm{CO}\right)$ in a spark-ignition directinjection engine. Part 1: combustion, performance and emissions comparison with CNG, Int J Hydrogen Energy 2014; 39:17884-17895.

29. Day MS, Bell JB, Gao X, Glarborg P. Numerical simulation of nitrogen oxide formation in lean premixed turbulent $\mathrm{H}_{2} / \mathrm{O}_{2} / \mathrm{N}_{2}$ flames. Proc Combust Inst 2011; 33: 1591-1599.

30. Lee UD, Yoo CS, Chen JH, Frank JH. Effect of NO on extinction and re-ignition of vortex-perturbed hydrogen flames. Combust Flame 2010; 157: 217-229. 
31. Hilbert R, Thevenin D. Influence of differential diffusion on maximum flame temperature in turbulent nonpremixed hydrogen/air flames. Combust Flame 2004; 138: 175-187.

32. Yoo CS, Sankaran R, Chen JH. Three-dimensional direct numerical simulation of a turbulent lifted hydrogen jet flame in heated co-flow: flame stabilization and structure. $\mathrm{J}$ Fluid Mech 2009; 640: 453-481.

33. van Oijen JA. Direct numerical simulation of autoigniting mixing layers in MILD combustion. Proc Combust Inst 2013; 34: 1163-1171.

34. Westbrook CK, Mizobuchi Y, Poinsot TJ, Smith PJ, Warnatz J. Computational combustion. Proc Combust Inst 2005; 30: 125-157.

35. Chen JH. Petascale direct numerical simulation of turbulent combustion- fundamental insights towards predictive models. Proc Combust Inst 2011; 33: 99-123.

36. van Oijen JA, de Goey LPH. Modelling of premixed laminar flames using flameletgenerated manifolds. Combust Sci Tech 2000; 161: 113-137.

37. Ranga Dinesh KKJ, Jiang X, van Oijen JA, Bastiaans RJM, de Goey LPH. Influence of fuel variability on the characteristics of impinging nonpremixed syngas burning. Proc Combust Inst 2013; 34: 3219-3229.

38. Ranga Dinesh KKJ, Jiang X, van Oijen JA, Bastiaans RJM, de Goey LPH. Hydrogenenriched nonpremixed jet flames: effects of preferential diffusion. Int J Hydrogen Energy 2013; 38: 4848-4863.

39. Ranga Dinesh KKJ, Jiang X, van Oijen JA. Hydrogen-enriched non-premixed jet flames: compositional structures with near-wall effects. Int J Hydrogen Energy 2013; 38: 5150-5164. 40. Ranga Dinesh KKJ, Jiang X, van Oijen JA. Hydrogen-enriched non-premixed jet flames: analysis of the flame surface, flame normal, flame index and Wobbe index. Int $\mathbf{J}$ Hydrogen Energy 2014; 39: 6753-6763. 
607

608

41. Ranga Dinesh KKJ, Jiang X, van Oijen JA. Near-field local flame extinction of oxysyngas non-premixed jet flames: a DNS study. Fuel 2014; 130: 189-196.

42. Peters N.Turbulent combustion. Cambridge Uni. Press. 2000.

43. Smith GP, Golden DM, Frenklach M, Moriarty NW, Eiteneer B, Goldenberg M, Bowman CT, Hanson RK, Song S, Gardiner WC, Lissianski VV, Qin Z, <http://www.me.berkeley.edu/gri_mech>.

44. Luo KH. Combustion effects on turbulence in a partially premixed supersonic diffusion flame. Combust Flame 1999; 119: 417-435.

45. Lele SK. Compact finite difference schemes with spectral-like resolution. J of Comput Phy 1992; 103: 16-42.

46. Williamson JH. Low-storage Runge-Kutta schemes. J of Comput Phy 1980; 35: 48-56.

47. Poinsot TJ, Lele SK. Boundary conditions for direct simulations of compressible viscous flows. J of Comput Phy 1992; 101: 104-129.

48. Zeldovich YB. The oxidation of nitrogen in combustion and explosions, Acta Physicochim 1946; 21: 577-628.

49. Fenimore CP. Formation of nitric oxide in premixed hydrocarbon flames. Symposium (Int) on Combustion 1971; 13: 373-380.

50. Wolfrum J. Bildung von Stickstoffoxiden bei der Verbrennung. Chem Ing-Tech 1972; $44: 656-659$.

51. Bozzelli JW, Dean AM. O+ NNH: A possible new route for NOx formation in flames. Int J Chem Kinet 1995; 27: 1097-1109.

52. Moskaleva LV, Lin MC. The spin-conserved reaction $\mathrm{CH}+\mathrm{N} 2 \rightarrow \mathrm{H}+\mathrm{NCN}$ : A major pathway to prompt no studied by quantum/statistical theory calculations and kinetic modelling of rate constant. Proc Combust Inst 2000; 28: 2393-2402. 
609 53. Konnov AA. Implementation of the NCN pathway of prompt-NO formation in the 610 detailed reaction mechanism. Combust Flame 2009; 156: 2093-2105.

611 54. Konnov AA, Javed MT, Kassman H, Irfan N. NOx formation, control and reduction 612 techniques. first ed. Wiley-VCH, 2010.

613

614

615

616

617

618

619

620

621

622

623

624

625

626

627

628

629

630

631

632

633 
Tables:

635 Table 1. Simulated test cases, flame properties, physical and numerical parameters.

\begin{tabular}{|c|c|c|c|}
\hline $\begin{array}{l}\text { Simulated Flames, } \\
\text { Properties and } \\
\text { Parameters }\end{array}$ & Flame H & Flame HCO1 & Flame HCO2 \\
\hline Fuel Properties & $100 \% \mathrm{H}_{2}$ by volume & $\begin{array}{l}70 \% \mathrm{H}_{2} \text { by volume } \\
30 \% \mathrm{CO} \text { by volume }\end{array}$ & $\begin{array}{l}50 \% \mathrm{H}_{2} \text { by volume } \\
50 \% \mathrm{CO} \text { by volume }\end{array}$ \\
\hline $\begin{array}{l}\text { Stoichiometric mixture } \\
\text { fraction }\end{array}$ & 0.028 & 0.124 & 0.179 \\
\hline $\begin{array}{l}\text { Adiabatic flame } \\
\text { temperature }\end{array}$ & $2637 \mathrm{~K}$ & $2480 \mathrm{~K}$ & $2434 K$ \\
\hline Jet Diameter (D) & $5 \mathrm{~mm}$ & $5 \mathrm{~mm}$ & $5 \mathrm{~mm}$ \\
\hline $\begin{array}{l}\text { Domain size } \\
\left(\mathrm{L}_{x} \times \mathrm{L}_{y} \times \mathrm{L}_{\mathrm{z}}\right)\end{array}$ & $\begin{array}{l}35 \mathrm{~m} \mathrm{~m} \times \\
35 \mathrm{~m} \mathrm{~m} \times \\
50 \mathrm{~m} \mathrm{~m}\end{array}$ & $\begin{array}{l}35 \mathrm{~m} \mathrm{~m} \times \\
35 \mathrm{~m} \mathrm{~m} \times \\
50 \mathrm{~m} \mathrm{~m}\end{array}$ & $\begin{array}{l}35 \mathrm{~m} \mathrm{~m} \times \\
35 \mathrm{~m} \mathrm{~m} \times \\
50 \mathrm{~m} \mathrm{~m}\end{array}$ \\
\hline $\begin{array}{l}\text { Number of grid points } \\
\left(\mathrm{N}_{x} \times \mathrm{N}_{\mathrm{y}} \times \mathrm{N}_{\mathrm{z}}\right)\end{array}$ & $\begin{array}{l}640 \times \\
640 \times \\
640\end{array}$ & $\begin{array}{l}640 \times \\
640 \times \\
640\end{array}$ & $\begin{array}{l}640 \times \\
640 \times \\
640\end{array}$ \\
\hline $\begin{array}{l}\text { Mean inlet jet velocity } \\
\left(U_{j}\right)\end{array}$ & $\begin{array}{l}20.94 \\
\mathrm{~m} \mathrm{~s}^{-1}\end{array}$ & $\begin{array}{l}20.94 \\
\mathrm{~m} \mathrm{~s}^{-1}\end{array}$ & $\begin{array}{l}20.94 \\
\mathrm{~m} \mathrm{~s}^{-1}\end{array}$ \\
\hline Inlet Jet temperature & $300 \mathrm{~K}$ & $300 \mathrm{~K}$ & $300 \mathrm{~K}$ \\
\hline $\begin{array}{l}\text { Jet Reynolds number }{ }^{1} \\
\left(\mathrm{Re}=\mathrm{U}_{\mathrm{j}} \times \mathrm{D} / v\right)\end{array}$ & 6000 & 6000 & 6000 \\
\hline $\begin{array}{l}\text { Velocity fluctuation }{ }^{2} \\
\left(\mathrm{u}^{\prime} / \mathrm{U}_{\mathrm{j}}\right)\end{array}$ & 0.23 & 0.21 & 0.2 \\
\hline $\begin{array}{l}\text { Integral length } \\
\text { scale }^{2,3}\left(1_{33} / \mathrm{D}\right)\end{array}$ & 0.36 & 0.37 & 0.39 \\
\hline $\begin{array}{l}\text { Turbulence Reynolds } \\
\text { number }^{2,3}\left(\mathrm{Re}_{\mathrm{t}}=\mathrm{u}^{\prime} l_{33} / v\right)\end{array}$ & 230 & 224 & 218 \\
\hline
\end{tabular}


$636{ }^{1}$ Kinematic viscosity at the inflow conditions, $v=1.574 \mathrm{e}-05 \mathrm{~m}^{2} \mathrm{~s}^{-1}$ is used to calculate the 637 Reynolds number.

$638{ }^{2}$ The turbulence scales evolve from the artificial turbulence specified at the inflow. The $639 \mathrm{u}$ ' value is evaluated at the $1 / 2$ stream location along the jet centreline.

$640{ }^{3}$ Integral length scale $1_{33}$ is defined as the integral of the auto-correlation of the spanwise 641 component of velocity in the spanwise direction. The $\mathrm{u}^{\prime}$ value is evaluated at the $1 / 2$ stream 642 location along the jet centreline.

643

644

645

646

647

648

649

650

651

652

653

654

655

656

657

658

659

660

661

662

663

664

665

666

667

668

669

670

671

672

673

674

675

676

677

678

679

680 


\section{Figure Captions}

Fig.1. Configuration of the turbulent non-premixed round jet flame. Fuel is injected from the fuel inlet with a nozzle diameter D (here we show iso-contours of flame structure of hydrogen flame $\mathrm{H}$ and dashed line indicates the flammable layer).

Fig.2. Comparison of iso-contours of NO mass fraction, scatter plots of NO mass fraction vs. mixture fraction at full domain $(0 £ \mathrm{z} £ 10)$, and scatter plots of NO mass fraction vs. mixture fraction at near nozzle region $(z \leq 2)$ between unity Lewis number (a1, b1, c1) and non-unity Lewis number $(\mathrm{a} 2, \mathrm{~b} 2, \mathrm{c} 2)$ of hydrogen flame $\mathrm{H}$ at a non-dimensional time instant $\mathrm{t}=30$.

Fig.3. Comparison of scatter plots of NO mass fraction vs. mixture fraction of hydrogen flame $\mathrm{H}$ between DNS data (a1, b1, c1) at Reynolds number of 6000, and the experimental data (a2, b2, c2) at Reynolds number of 10000, at different non-dimensional axial locations $\mathrm{z}=4(\mathrm{a}), 8$ (b) and 10 (c).

Fig.4. Snapshots of flame temperature and NO mass fraction for flames $\mathrm{H}, \mathrm{HCO} 1$ and $\mathrm{HCO} 2$ at non-dimensional time $\mathrm{t}=30$.

Fig.5. Temperature (a) and net NO formation rate (b) as functions of mixture fraction for a low strain rate $a=1 s^{-1}$ and high strain rate $a=10^{4} s^{-1}$ for syngas flame HCO1.

Fig.6. Reaction rates of different NO formation mechanisms as functions of mixture fraction (a) for a low strain rate $a=1 s^{-1}$ and (b) for a high strain rate $a=10^{4} s^{-1}$ for syngas flame HCO1.

Fig.7. Scatter plots for flame temperature, NO mass fraction and source term of the transport equation of NO mass fraction vs. mixture fraction in near-inflow zone A $(0<z<2)$ for flames $\mathrm{H}, \mathrm{HCO} 1$ and $\mathrm{HCO} 2$ at non-dimensional time $\mathrm{t}=30$.

Fig.8. Scatter plots for flame temperature, NO mass fraction and source term of the transport equation of $\mathrm{NO}$ mass fraction vs. mixture fraction in intermediate zone $\mathrm{B}(2<\mathrm{z}<8)$ for flames $\mathrm{H}, \mathrm{HCO} 1$ and $\mathrm{HCO} 2$ at non-dimensional time $\mathrm{t}=30$.

Fig.9. Scatter plots for flame temperature, NO mass fraction and source term of the transport equation of NO mass fraction vs. mixture fraction in near-outflow zone $\mathrm{C}(8<\mathrm{z}<10)$ for flames $\mathrm{H}, \mathrm{HCO} 1$ and $\mathrm{HCO} 2$ at non-dimensional time $\mathrm{t}=30$.

Fig.10. Conditional mean values of mass fractions of $\mathrm{NO}$ as a function of temperature for flames $\mathrm{H}, \mathrm{HCO} 1$ and $\mathrm{HCO} 2$ at non-dimensional time $\mathrm{t}=30$.

Fig.11. Probability density function (pdf) of temperature for flames $\mathrm{H}, \mathrm{HCO} 1$ and $\mathrm{HCO} 2$ at non-dimensional time $\mathrm{t}=30$.

Fig.12. Probability density function (pdf) of mass fractions of NO for flames H, HCO1 and $\mathrm{HCO} 2$ at non-dimensional time $\mathrm{t}=30$. 
Figures:

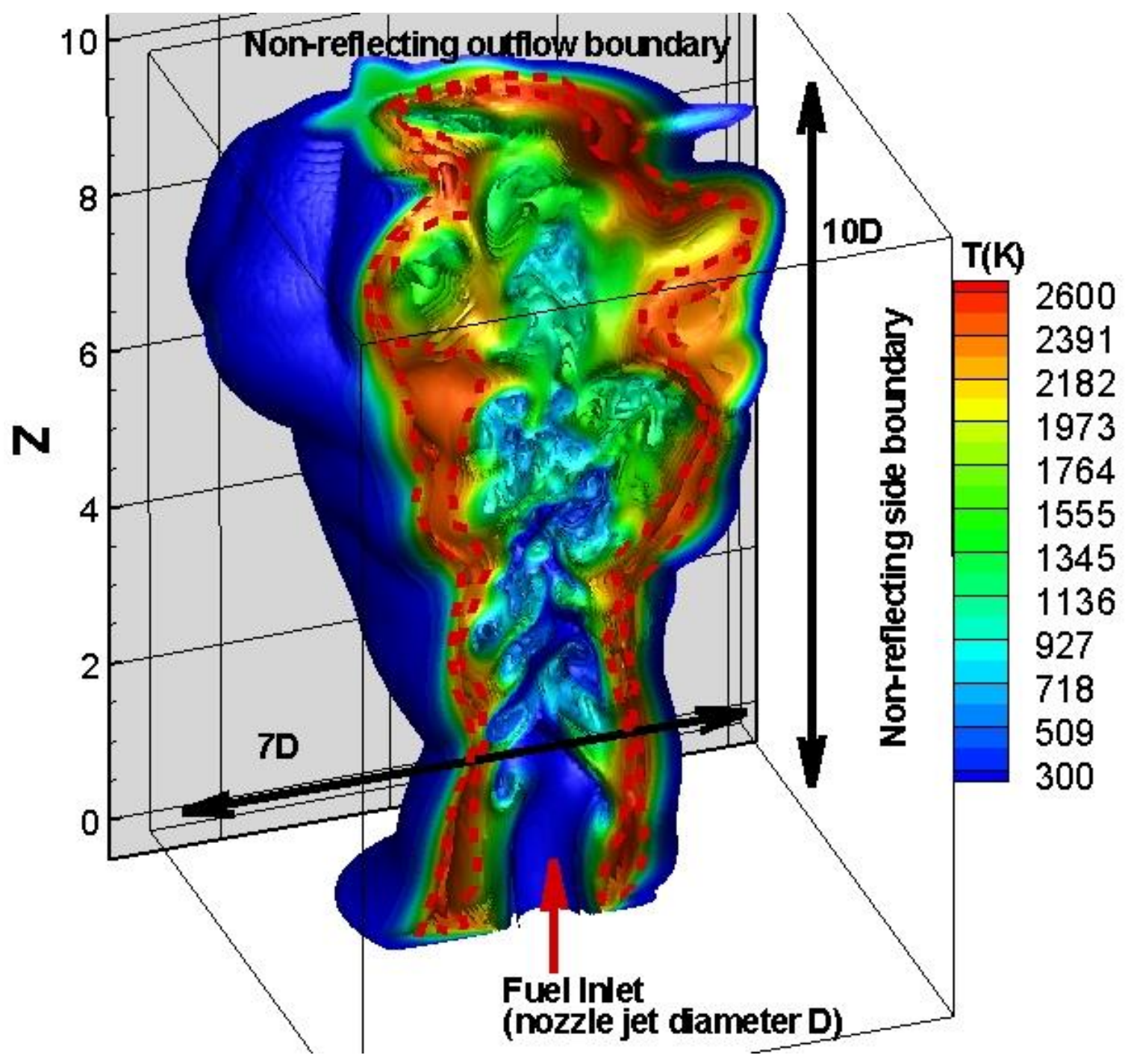

Fig.1. Configuration of the turbulent non-premixed round jet flame. Fuel is injected from the fuel inlet with a nozzle diameter D (here we show iso-contours of flame structure of hydrogen flame $\mathrm{H}$ and dashed line indicates the flammable layer). 

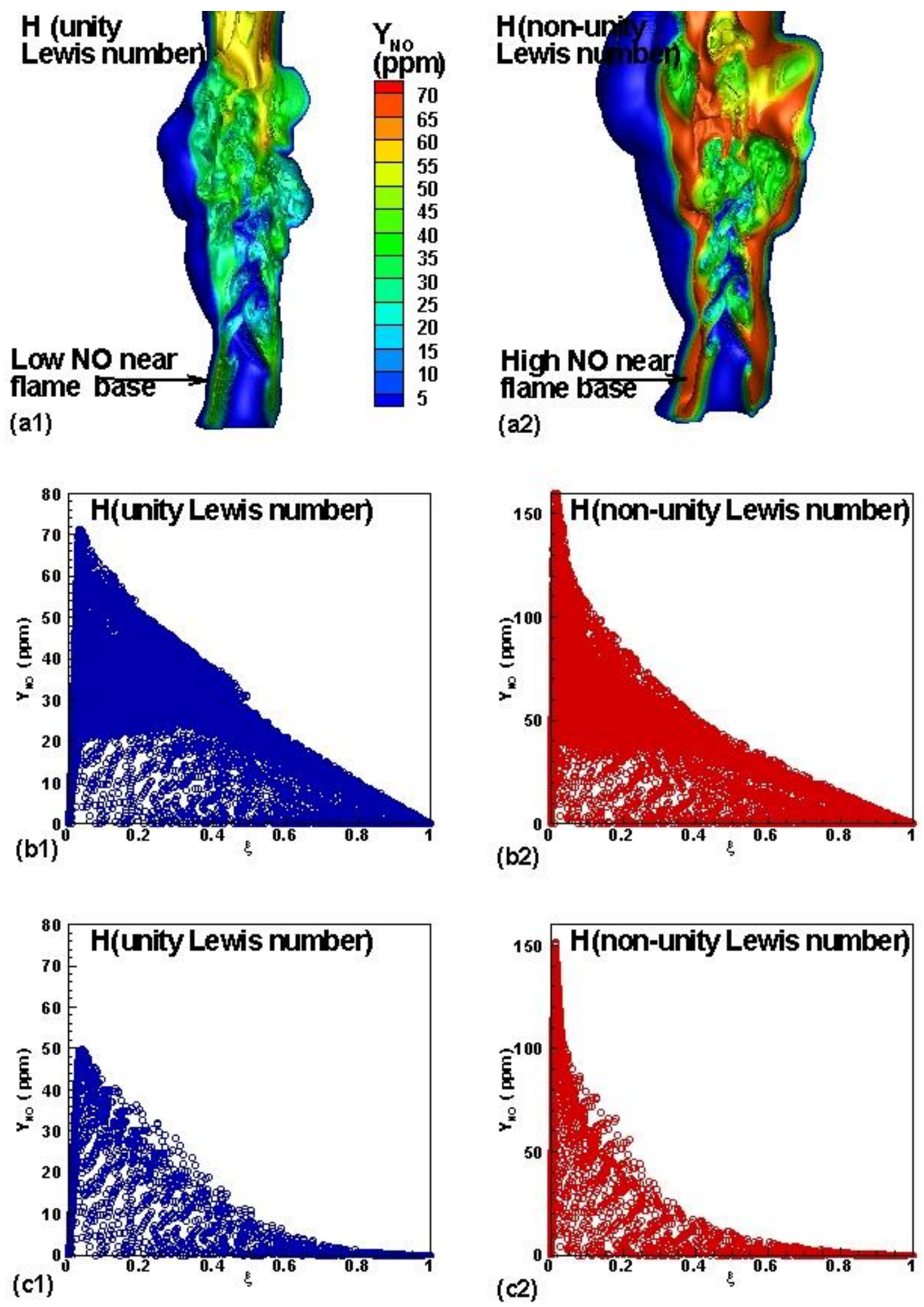

732 Fig.2. Comparison of iso-contours of NO mass fraction, scatter plots of NO mass fraction vs. 733 mixture fraction at full domain ( $0 £ \mathrm{z} £ 10)$, and scatter plots of NO mass fraction vs. 734 mixture fraction at near nozzle region $(z \leq 2)$ between unity Lewis number (a1, b1, c1) and 735 non-unity Lewis number $(\mathrm{a} 2, \mathrm{~b} 2, \mathrm{c} 2)$ of hydrogen flame $\mathrm{H}$ at a non-dimensional time instant $736 \mathrm{t}=30$. 

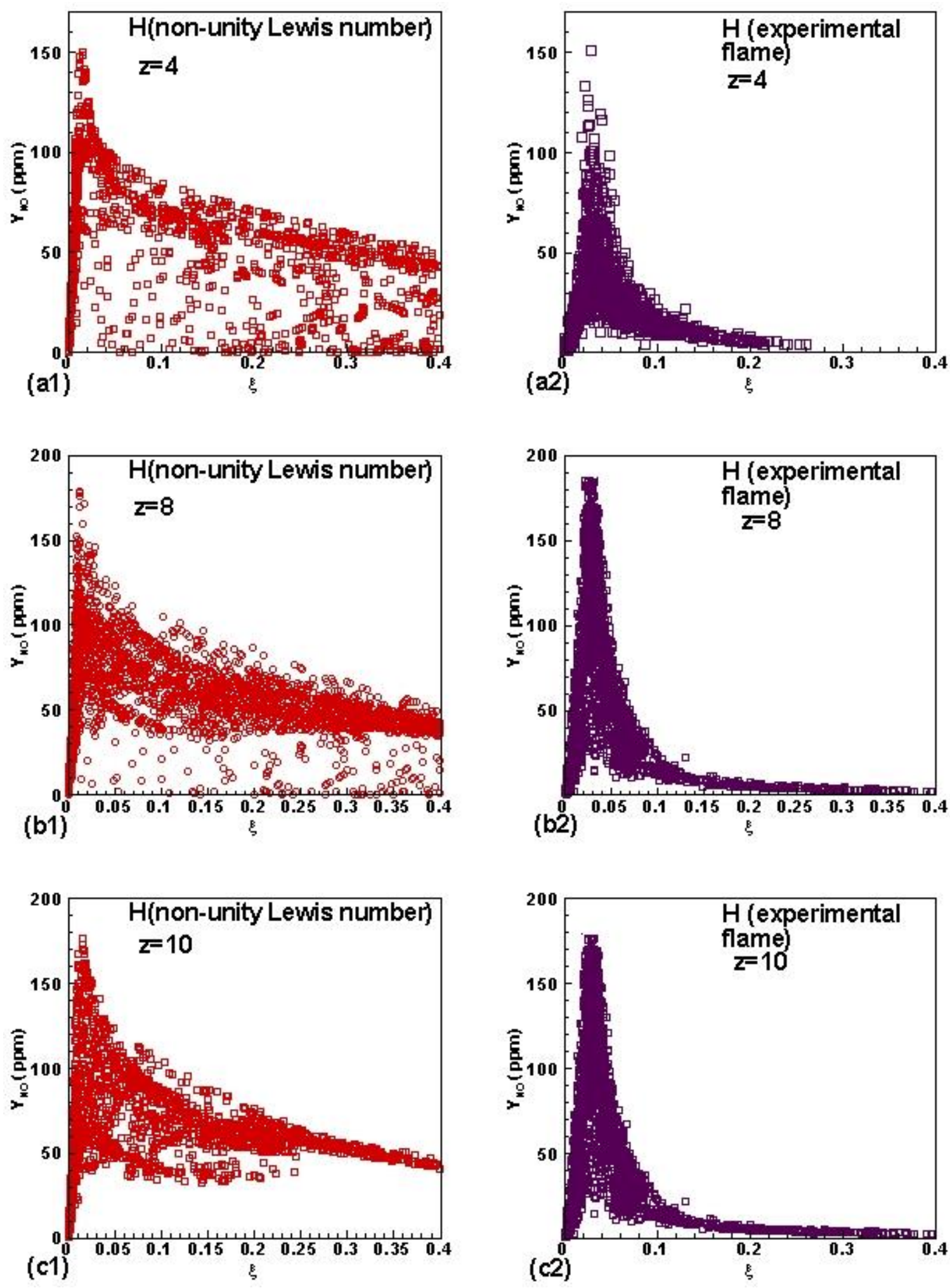

738 Fig.3. Comparison of scatter plots of NO mass fraction vs. mixture fraction of hydrogen 739 flame $\mathrm{H}$ between DNS data (a1, b1, c1) at Reynolds number of 6000, and the experimental 740 data (a2, b2, c2) at Reynolds number of 10000, at different non-dimensional axial locations $741 \mathrm{z}=4(\mathrm{a}), 8(\mathrm{~b})$ and $10(\mathrm{c})$. 

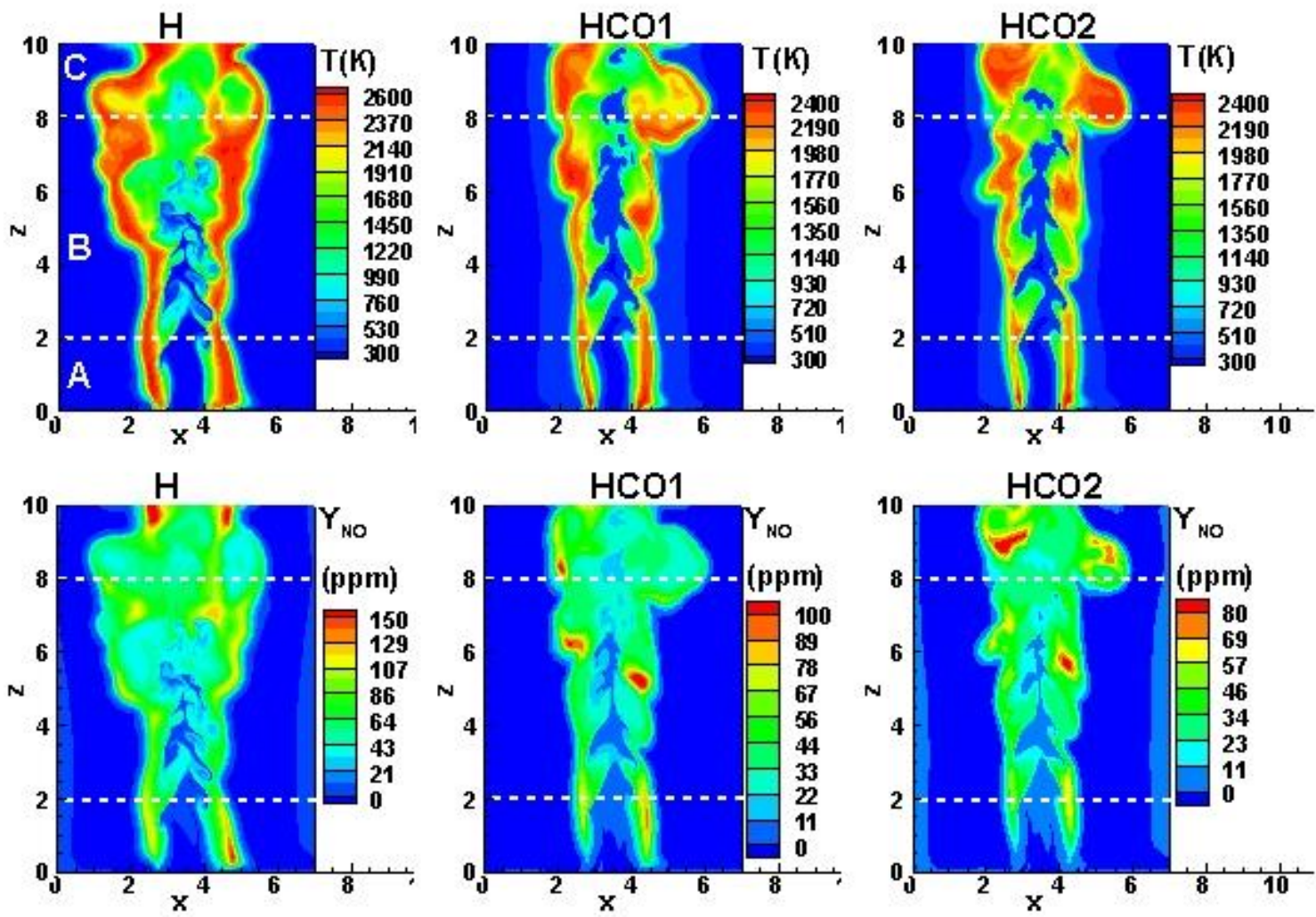

Fig.4. Snapshots of flame temperature and $\mathrm{NO}$ mass fraction for flames $\mathrm{H}, \mathrm{HCO} 1$ and $\mathrm{HCO} 2$ at non-dimensional time $\mathrm{t}=30$. 


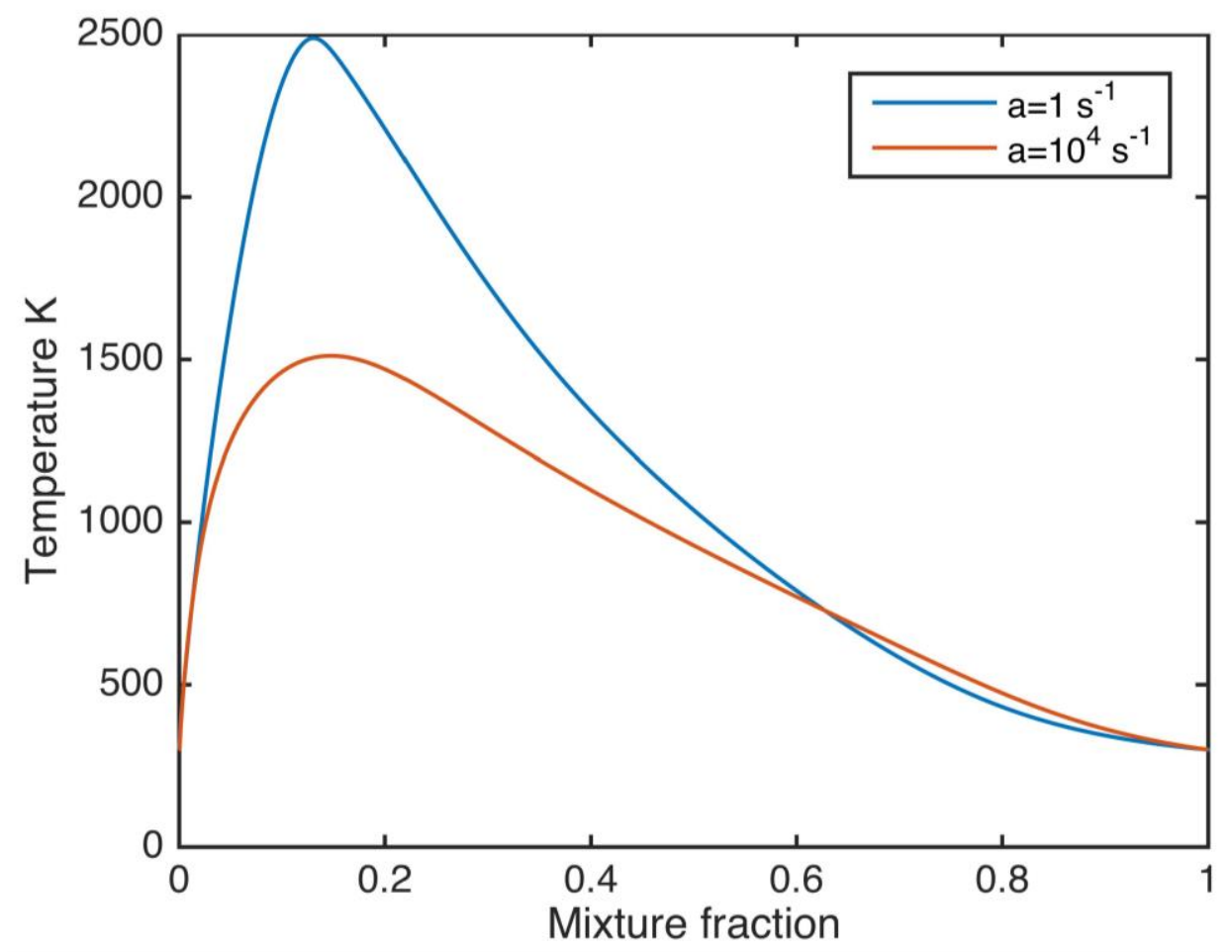

758

(a)

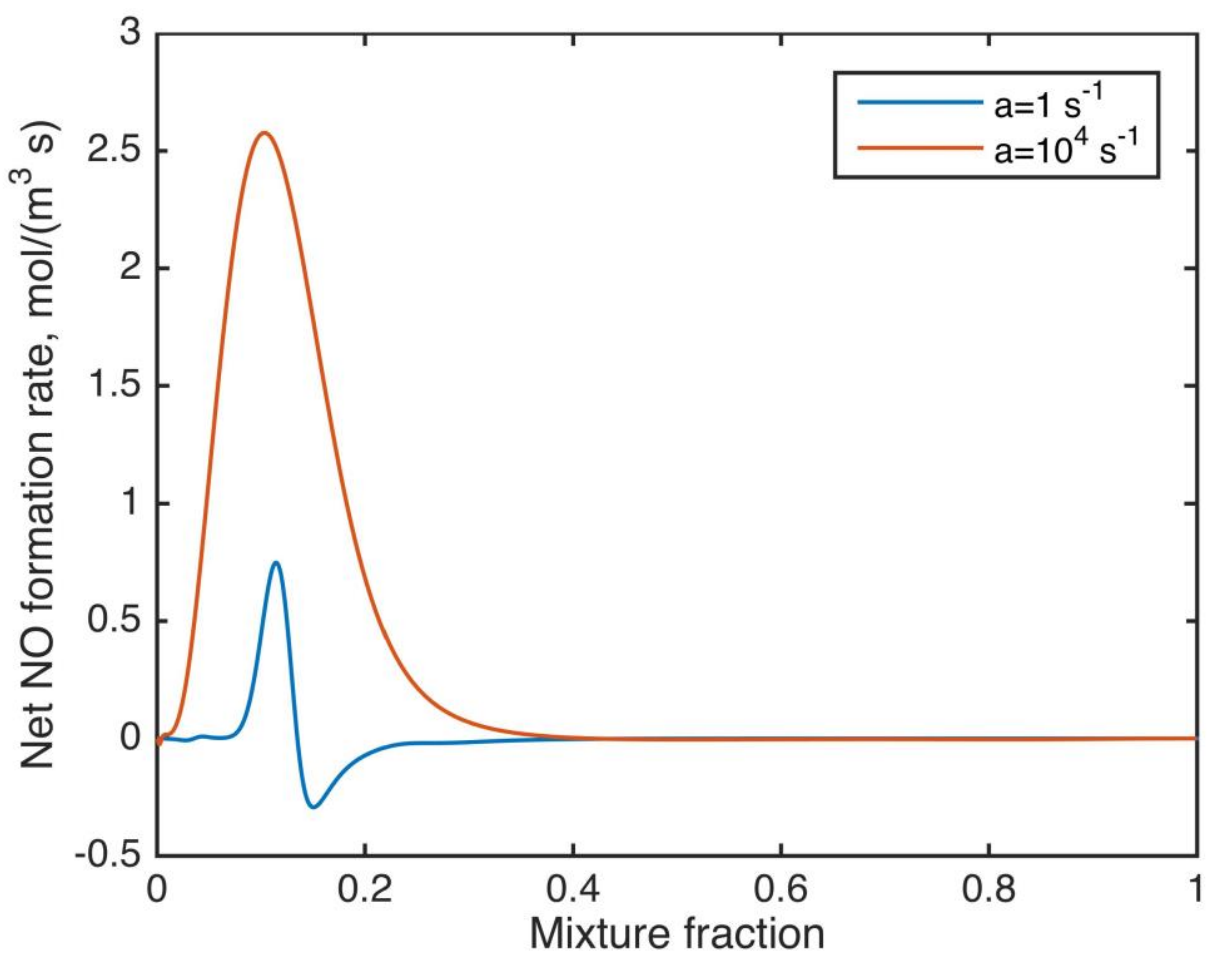

(b)

763 Fig.5. Temperature (a) and net NO formation rate (b) as functions of mixture fraction for a 764 low strain rate $a=1 s^{-1}$ and high strain rate $a=10^{4} s^{-1}$ for syngas flame HCO1. 


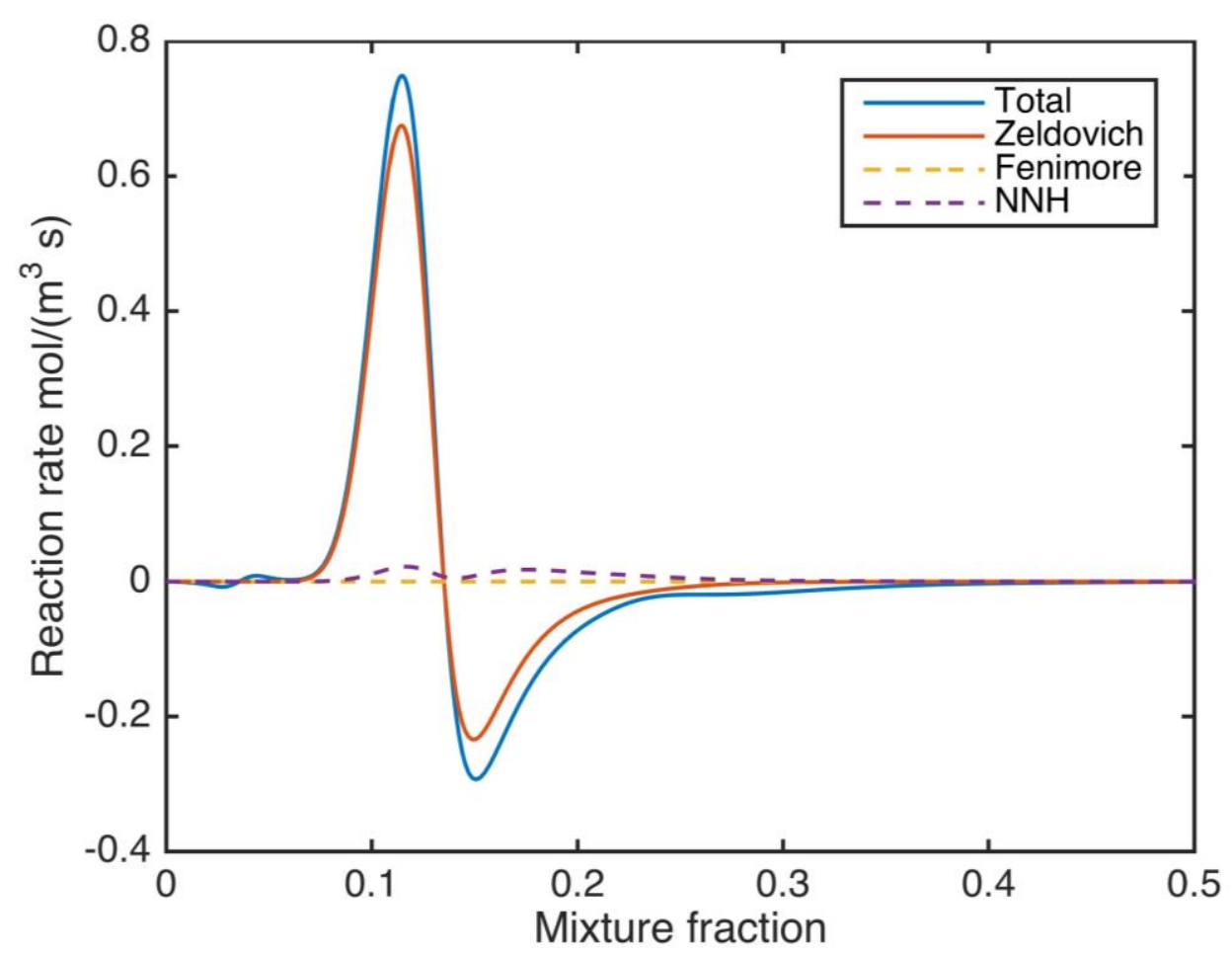

765

766

(a)

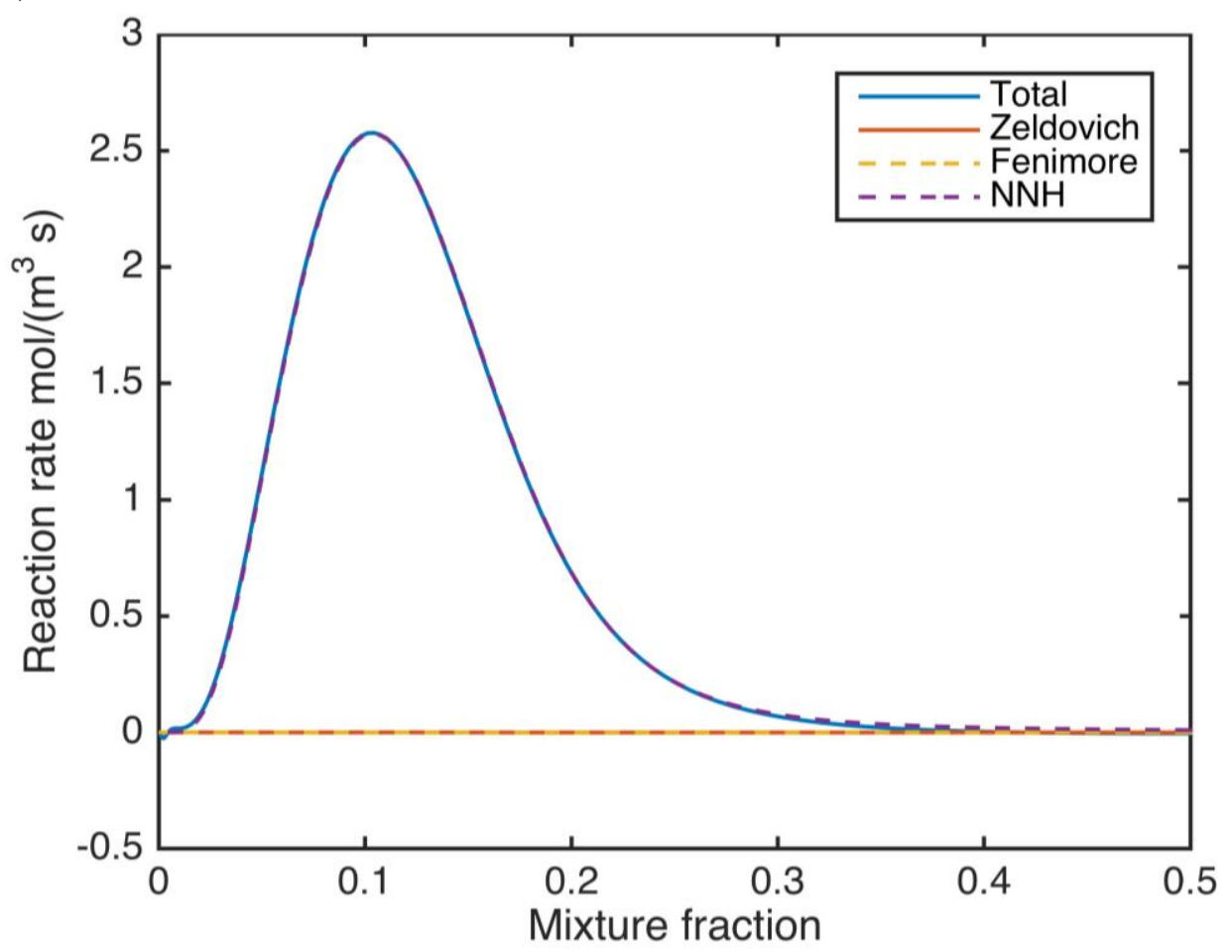

(b)

770 Fig.6. Reaction rates of different NO formation mechanisms as functions of mixture fraction 771 (a) for a low strain rate $a=1 s^{-1}$ and (b) for a high strain rate $a=10^{4} s^{-1}$ for syngas flame 772 HCO1. 

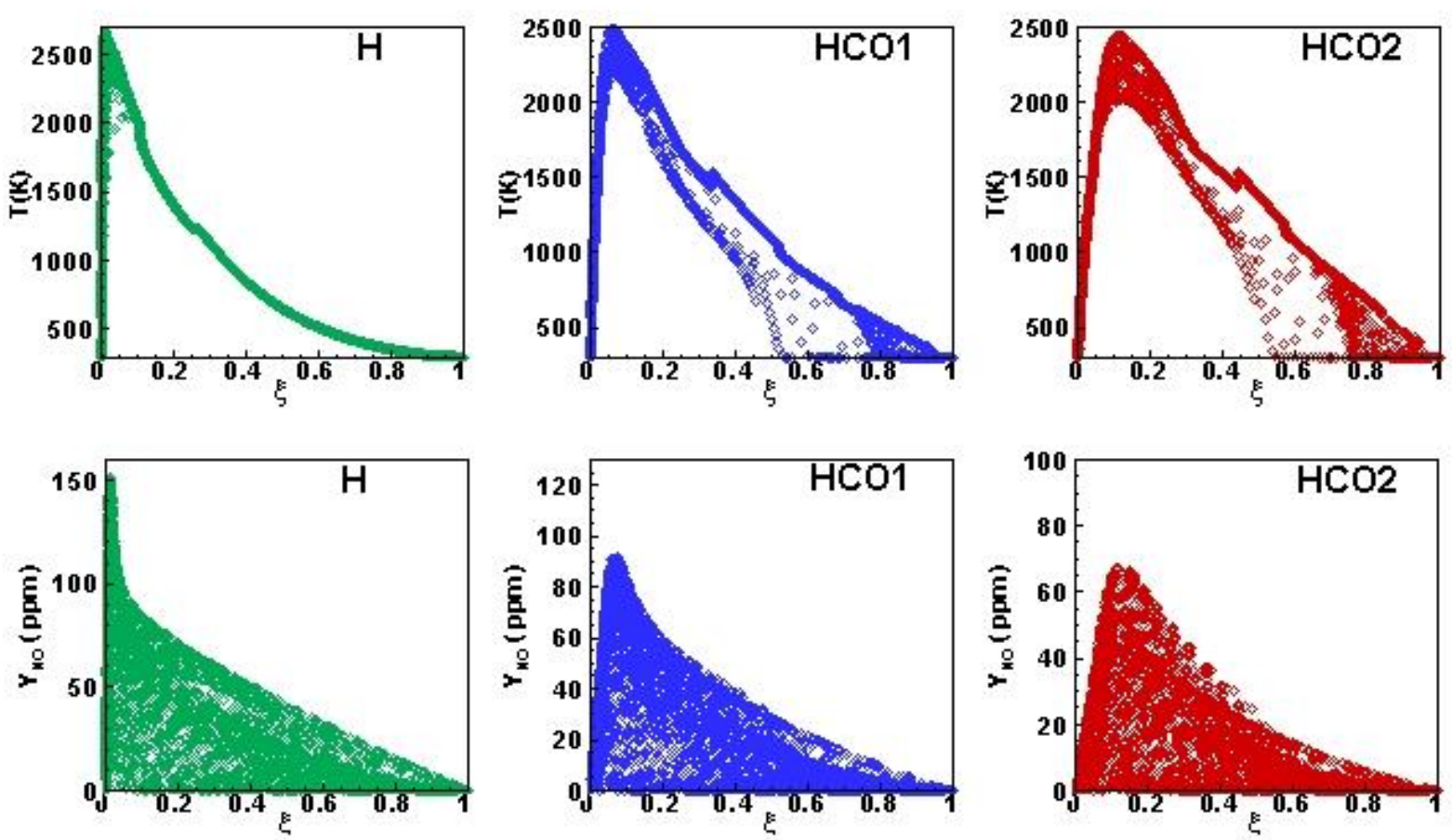

775
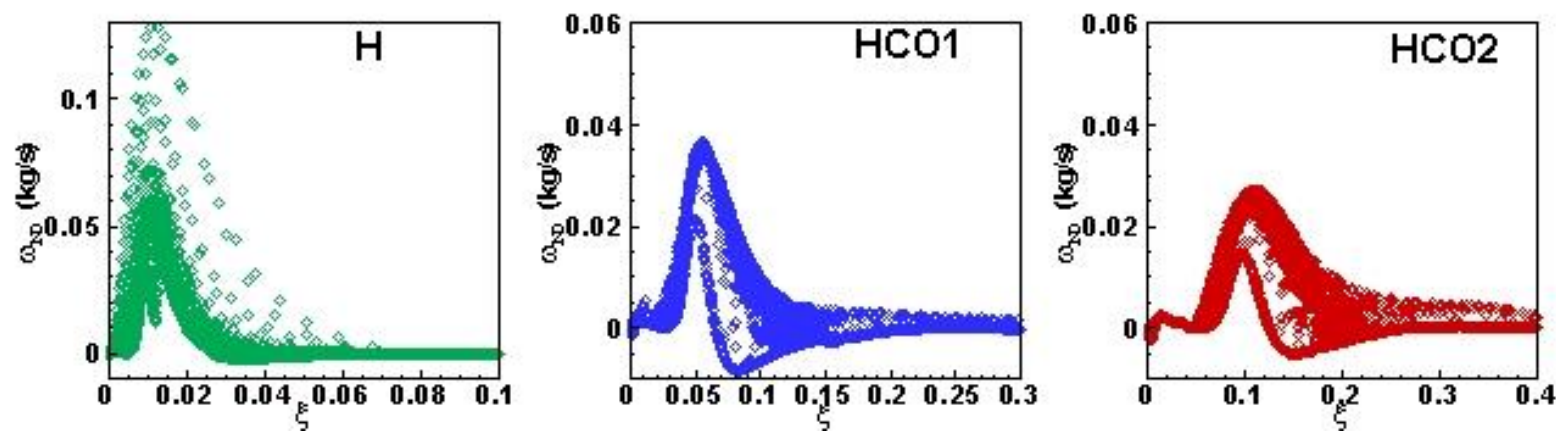

Fig.7. Scatter plots for flame temperature, NO mass fraction and source term of the transport equation of NO mass fraction vs. mixture fraction in near-inflow zone A $(0<z<2)$ for flames $\mathrm{H}, \mathrm{HCO} 1$ and $\mathrm{HCO} 2$ at non-dimensional time $\mathrm{t}=30$. 

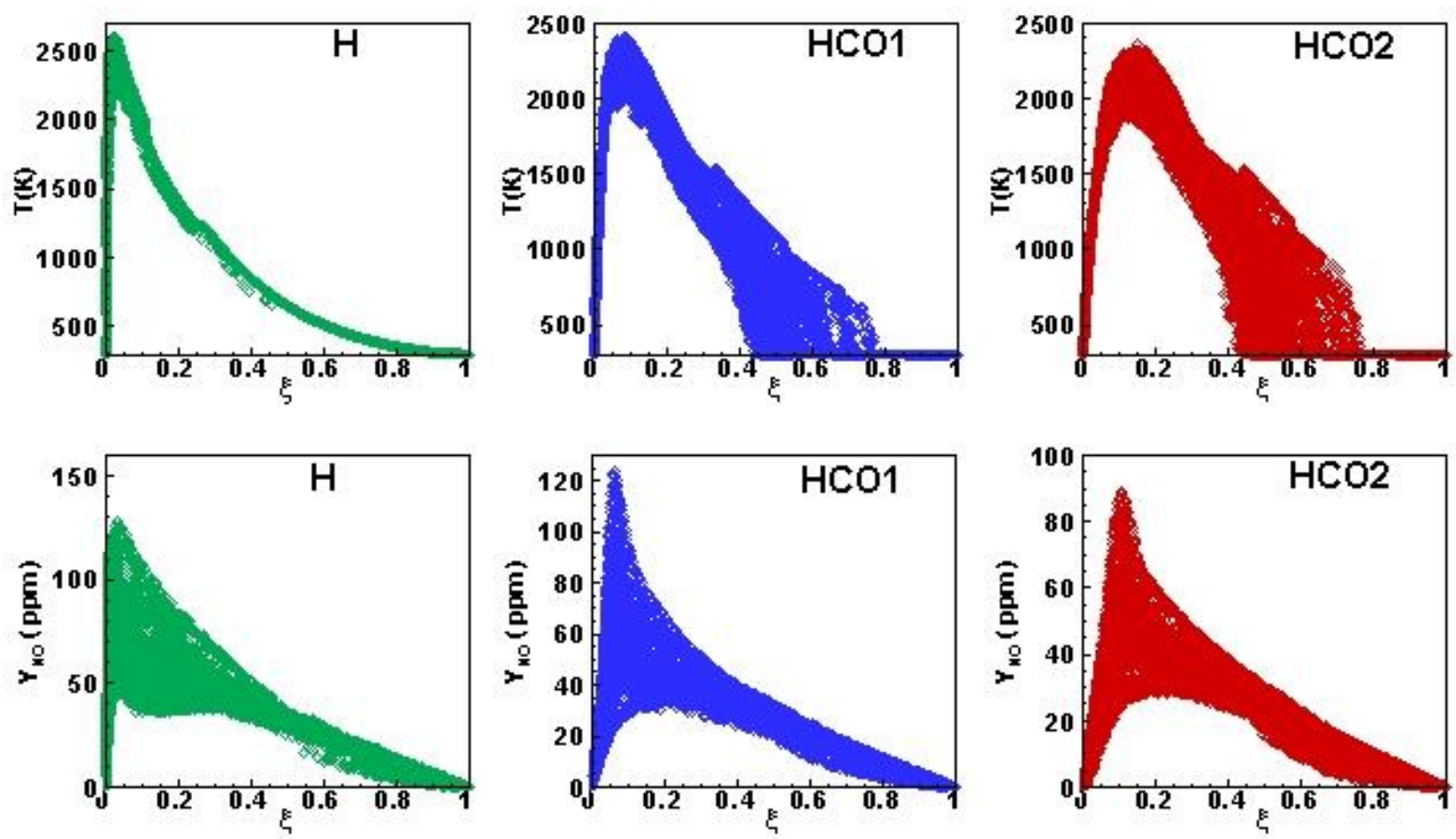

787
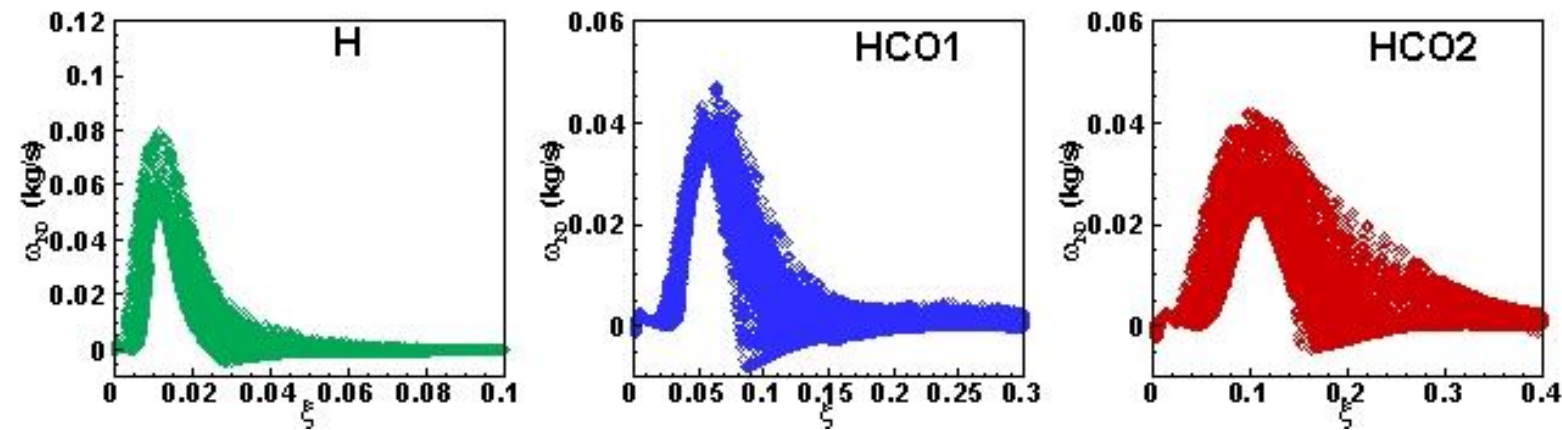

Fig.8. Scatter plots for flame temperature, NO mass fraction and source term of the transport equation of $\mathrm{NO}$ mass fraction vs. mixture fraction in intermediate zone $\mathrm{B}(2<\mathrm{z}<8)$ for flames $\mathrm{H}, \mathrm{HCO} 1$ and $\mathrm{HCO} 2$ at non-dimensional time $\mathrm{t}=30$. 

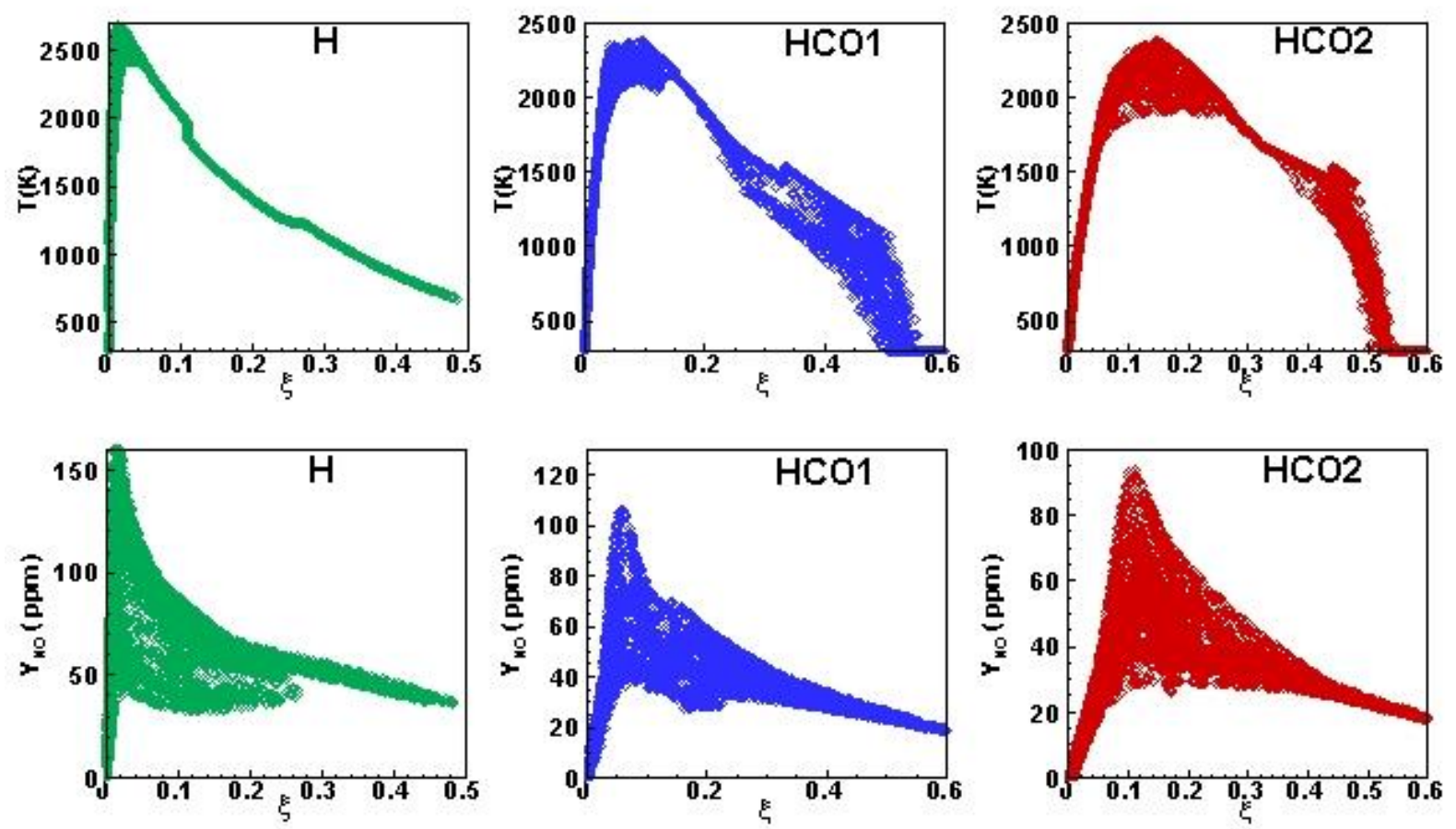

799
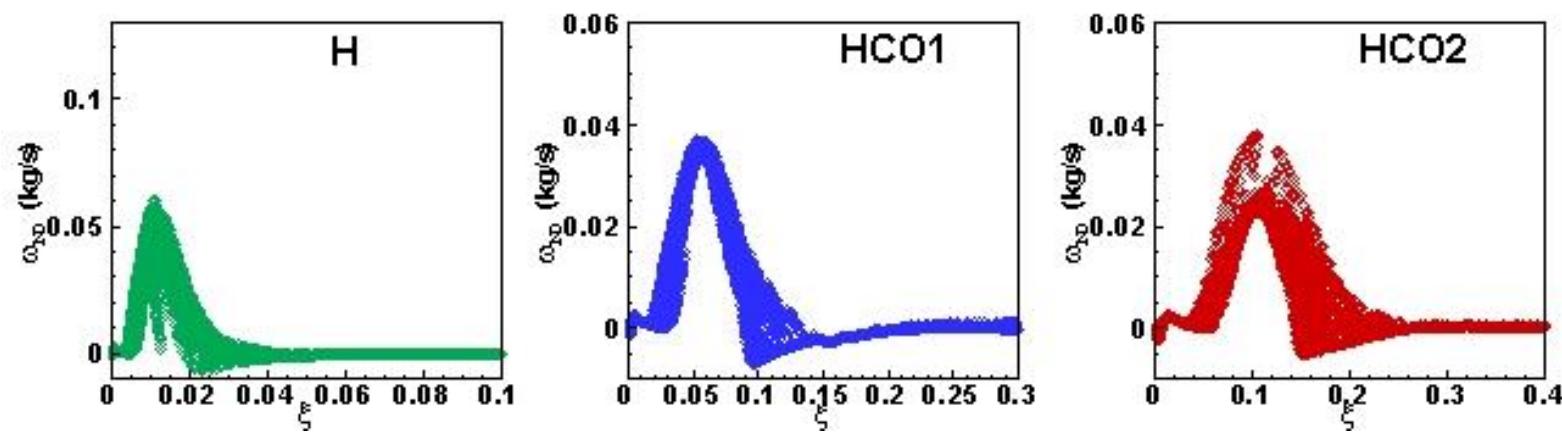

Fig.9. Scatter plots for flame temperature, NO mass fraction and source term of the transport equation of $\mathrm{NO}$ mass fraction vs. mixture fraction in near-outflow zone $\mathrm{C}(8<\mathrm{z}<10)$ for flames $\mathrm{H}, \mathrm{HCO} 1$ and $\mathrm{HCO} 2$ at non-dimensional time $\mathrm{t}=30$. 


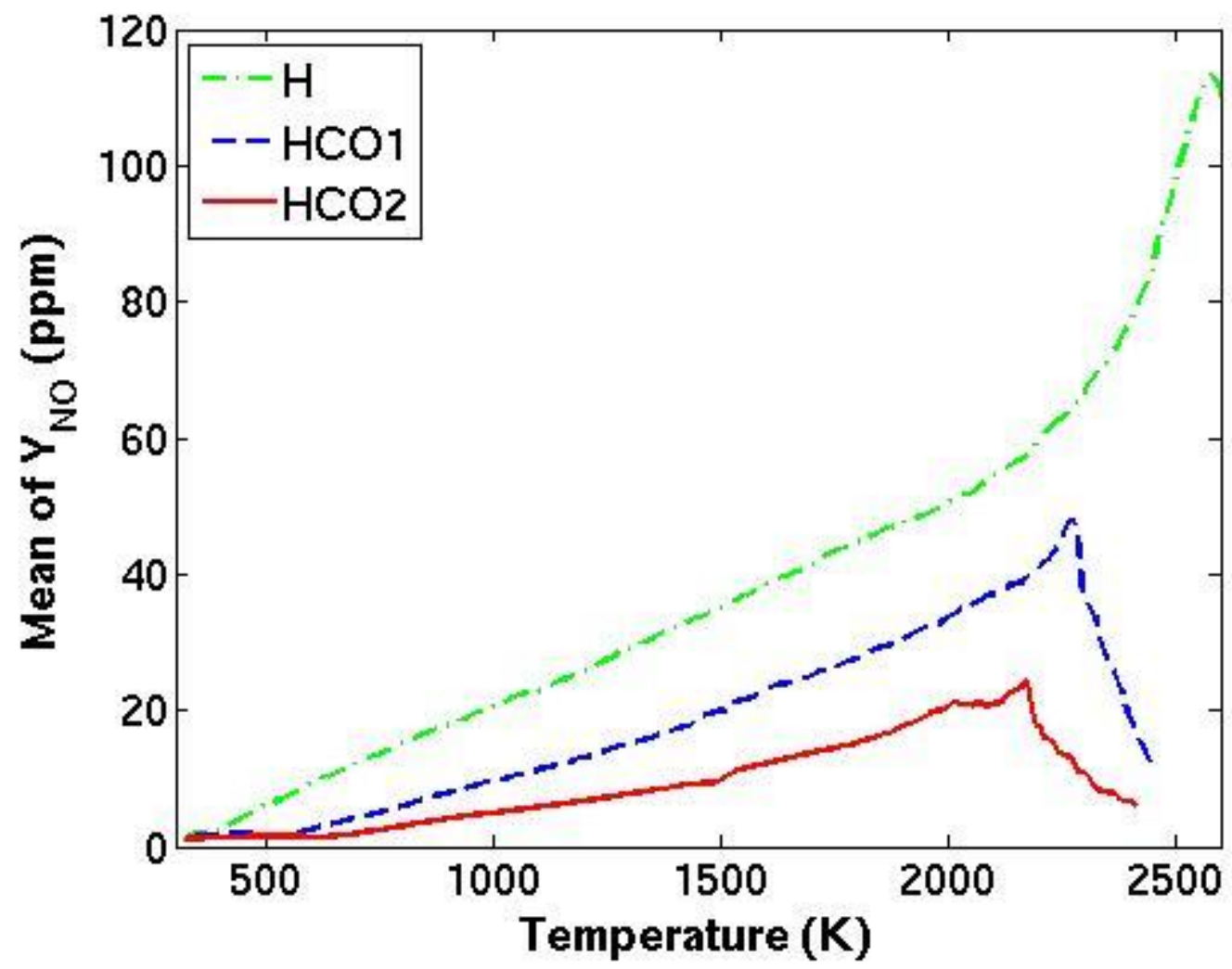

812 Fig.10. Conditional mean values of mass fractions of NO as a function of temperature for 813 flames $\mathrm{H}, \mathrm{HCO} 1$ and $\mathrm{HCO} 2$ at non-dimensional time $\mathrm{t}=30$.

814

815

816

817

818

819

820

821

822

823

824 


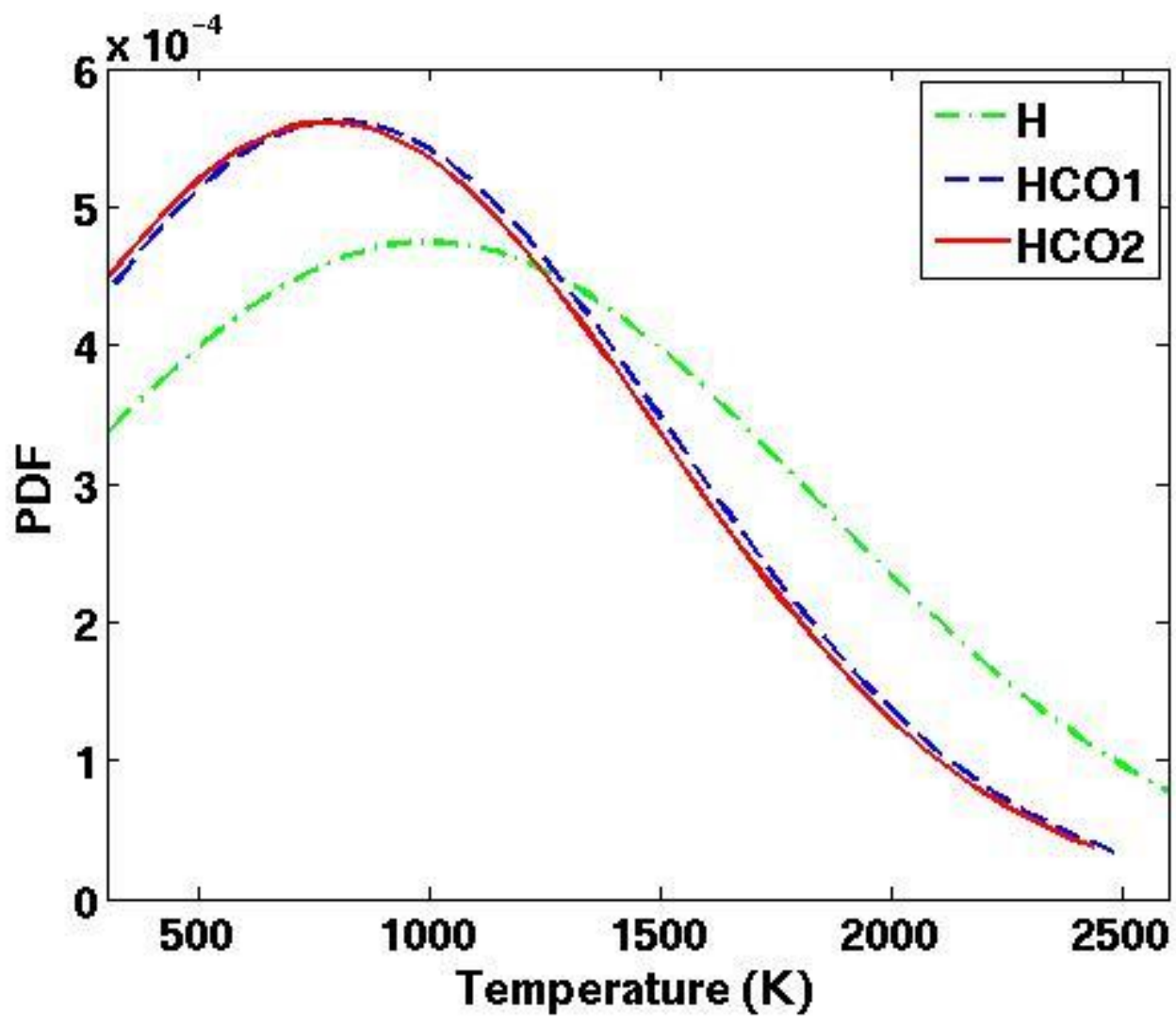

827 Fig.11. Probability density function (pdf) of temperature for flames H, HCO1 and HCO2 at 828 non-dimensional time $\mathrm{t}=30$.

829

830

831 


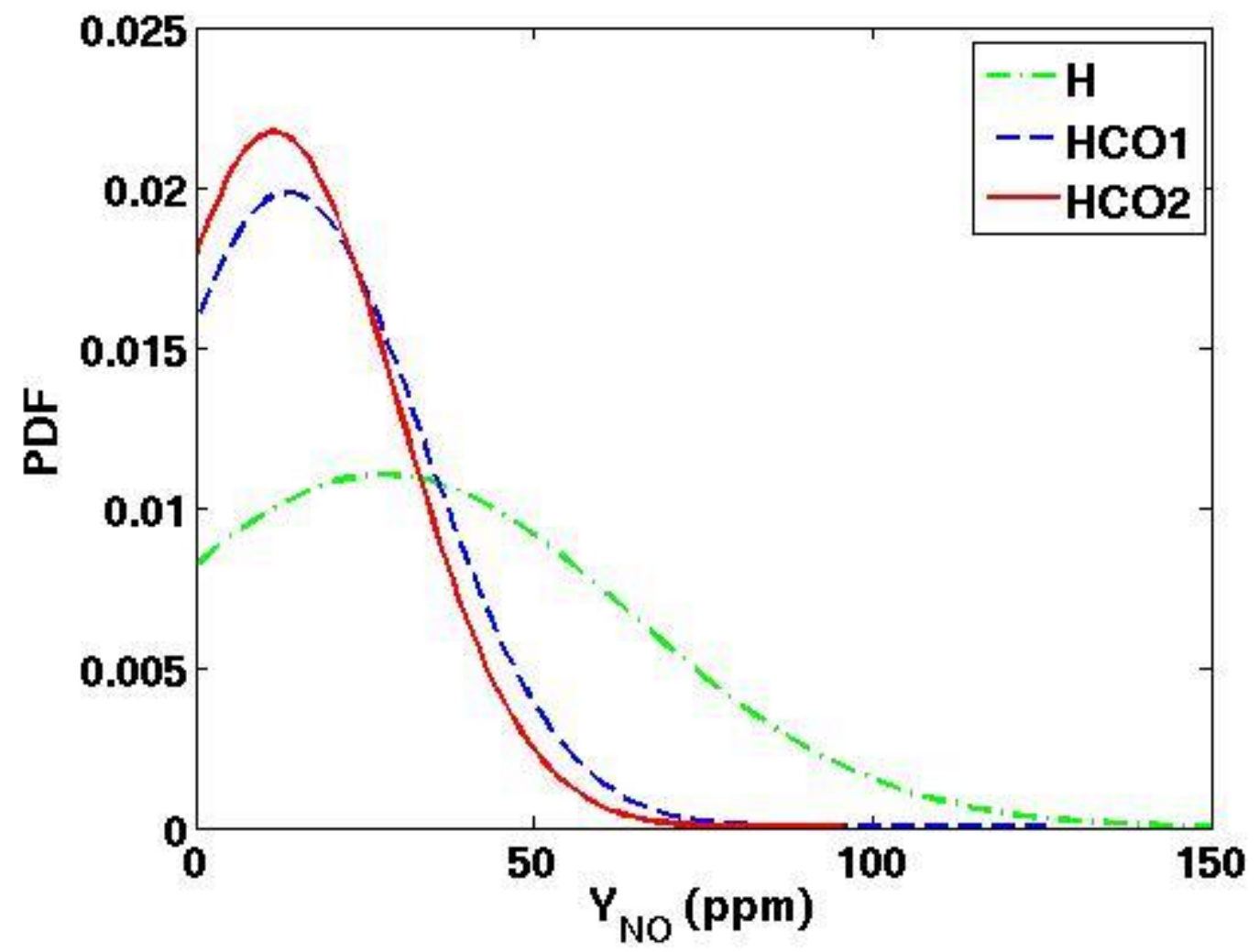

Fig.12. Probability density function (pdf) of mass fractions of $\mathrm{NO}$ for flames $\mathrm{H}, \mathrm{HCO} 1$ and $\mathrm{HCO} 2$ at non-dimensional time $\mathrm{t}=30$. 